\title{
A literatura a respeito da comparação entre a teoria das restrições e a manufatura enxuta: revisão, classificação e análise
}

\author{
Literature on the comparison between the theory of constraints and \\ lean manufacturing: review, classification, and analysis
}

\author{
Marcel Heimar Ribeiro Utiyama ${ }^{1}$ \\ Moacir Godinho Filho'
}

\begin{abstract}
Resumo: Neste trabalho, é realizada uma revisão da literatura completa (33 artigos) a respeito da comparação entre a Teoria das Restrições (TOC) e a Manufatura Enxuta.Comparações entre ambas as abordagens é um tema pouco abordado na literatura de Gestão e Produção, sendo que não existe uma extensa revisão sobre ele. A partir da revisão, é proposto um sistema de classificação baseado em 4 parâmetros: fonte do trabalho; método de pesquisa; abrangência; e resultados da comparação. Depois da classificação dos trabalhos, utilizando o sistema de classificação proposto, foi realizada a análise do tema. Nesta análise, foi observado que o número de trabalhos que realizam uma comparação ampla entre a Teoria das Restrições e a Manufatura Enxuta é predominante, assim como aqueles que afirmam que uma determinada abordagem se sobressai em alguma situação específica. Vale ressaltar que existe um grande número de trabalhos que defendem que as abordagens e/ou ferramentas de cada uma são na verdade complementares ou que buscam integrá-las. Por fim, foi observado ao longo dessa revisão que não é possível afirmar que um das abordagens/ferramentas seja melhor, pois, mesmo com a predominância de trabalhos afirmando que a TOC/Drum-Buffer-Rope se sobressai, nota-se que há situações em que a Manufatura Enxuta/Kanban também prevalece. Portanto, é necessária uma correta avaliação da empresa e de seu ambiente, tornando possível escolher adequadamente uma abordagem, ou um híbrido entre elas, de modo a obter os ganhos esperados.
\end{abstract}

Palavras-chave: Teoria das restrições. Manufatura enxuta. Revisão. Comparação.

\begin{abstract}
In this study, a literature review (33 papers) on the comparison between the Theory of Constraints (TOC) and Lean Manufacturing is conducted. Comparisons between both approaches are rarely addressed in the literature of Production and Management, and there is not an extensive review on this topic. According to the literature review, a classification system is proposed based on four parameters: article source, research method, scope, and comparison results. After the articles' classification using the classification system proposed, an analysis of the topic was performed, which indicated that the number of papers that address a broad comparison between the Theory of Constraints and Lean Manufacturing is predominant, as well as those that claim that a particular approach excels in a specific situation. It is worth noting that there are a number of articles that argue that the approaches and/or their tools are in fact complementary or are aimed at their integration. Finally, the literature review indicated that it is not possible to state that one of the approaches/tools is the best because despite the predominance of articles arguing that the TOC/Drum-Buffer-Rope stands out from the others, there are situations where Lean Manufacturing/ Kanban is also prevalent. Therefore, is necessary a proper evaluation of each company and its environment to make it possible to carefully select a single or a hybrid approach in order to achieve the expected return.
\end{abstract}

Keywords: Theory of constraints. Lean manufacturing. Review. Comparison.

\section{Introdução}

Nos dias atuais, os gerentes de produção enfrentam muitos desafios: aumentar as vendas, reduzir os custos, reduzir estoques, dentre outros.Muitas abordagens (também denominadas por muitos autores filosofias de gestão) têm sido utilizadas pelas empresas para sobreviver e prosperar diante de tais desafios, dentre elas, destacam-se a Teoria das Restrições (GOLDRATT; COX, 1984) e o Sistema Toyota de Produção (MONDEN, 1986).

O objetivo deste trabalho é apresentar o que existe na literatura a respeito da comparação entre a Teoria das Restrições (TOC) e a Manufatura Enxuta. A Teoria

\footnotetext{
${ }^{1}$ Departamento de Engenharia da Produção, Centro de Ciências Exatas e de Tecnologia, Universidade Federal de São Carlos - UFSCar, Rod. Washington Luiz, Km 235, CP 676, CEP 13565-905, Sao Carlos, SP, Brasil, email: marcelc5@ yahoo.com.br; moacir@dep.ufscar.br
}

Recebido em 9/3/2011 — Aceito em 30/9/2011

Suporte financeiro: CAPES. 
das Restrições foi proposta primeiramente pelo Dr. Eliyahu Goldratt no livro A Meta (GOLDRATT; COX, 1984). Essa abordagem tem como objetivo fazer dinheiro agora como também no futuro (GOLDRATT; COX, 1984). A TOC enfatiza a importância do foco nas restrições, ou seja, fazer o que tem de ser feito e onde deve ser feito (GOLDRATT, 2010). Já o Sistema Toyota de Produção (STP), chamado no ocidente de Manufatura Enxuta (WOMACK; JONES; ROOS, 1991) surgiu por volta de 1950, no Japão, na empresa Toyota (LIKER, 2005). A base do Sistema Toyotade Produção é a absoluta eliminação dos desperdícios (OHNO, 1997), sendo que um dos pilares mais importantes de tal abordagem é o chamado Just In Time (MONDEN, 1986). Para os objetivos do presente trabalho, entendemos que Sistema Toyota de Produção, Manufatura Enxuta e Just In Time (JIT) são termos que caracterizam a mesma abordagem de gestão. Dessa forma, trabalhos referentes às três denominações estão inclusos em nossa pesquisa.

Dentre as muitas ferramentas utilizadas por ambas as abordagens, sobressaem às técnicas de planejamento e controle da produção: o Kanban utilizado na Manufatura Enxuta e o OPT (Optimized Production Technology) e/ou o DBR (drum-buffer-rope) na Teoria das restrições. Para os propósitos deste trabalho, tanto comparações entre ambas as abordagens quanto entre suas ferramentas de Planejamento e Controle da Produção (PCP) foram incluídas no estudo.

Para atingir seu objetivo, o presente trabalho realiza uma revisão da literatura que pretende ser completa a respeito da comparação entre as duas abordagens e suas ferramentas. Além disso, um sistema de classificação é proposto a fim de auxiliar na análise do tema estudado. Tal análise serve para fornecer maior conhecimento e perspectivas de trabalhos futuros na área.

O presente trabalho foi estruturado da seguinte forma: na seção 2, é apresentada a metodologia utilizada nesta pesquisa; na seção 3, é apresentado o sistema de classificação proposto, com os códigos utilizados; na seção 4, é apresentada a revisão da literatura a respeito da comparação entre as abordagens TOC e Manufatura Enxuta, estruturada de acordo com a classificação proposta; na seção 5,é feita uma análise sobre o tema proposto; e finalmente, na seção 6, são apresentadas algumas considerações finais.

\section{Metodologia de pesquisa}

Foi utilizada a metodologia teórico-conceitual para conduzir uma revisão da literatura a respeito da comparação entre a Teoria das Restrições e a Manufatura Enxuta. A revisão foi baseada na estrutura metodológica proposta por Godinho Filho e Fernandes (2003), mostrada na Figura 1.

A pesquisa foi realizada em diversas bases de dados, entre elas, o COMPENDEX, Google Acadêmico,
Web Of Science, Portal de Periódicos da Capes entre outros. Depois de uma pesquisa inicial, foram encontrados 33 artigos. Em seguida, foi desenvolvido um sistema de classificação, detalhado na seção 3, que foi utilizado para classificar os artigos da revisão bibliográfica de maneira mais conveniente (seção 4) e também realizar a análise do tema (seção 5). Essa análise possibilita melhor conhecimento do tema esugere perspectivas de trabalhos futuros.

Vale ressaltar que, apesar deste trabalho ter como propósito realizar uma revisão da literatura sobre a comparação entre JIT e TOC, outras abordagens permeiam essa revisão, pois alguns trabalhos fazem a comparação das duas abordagens de nosso interesse com outras abordagens/ferramentas, entre elas: MRP (MaterialsRequirement Planning), MRP II (Manufacturing Resource Planning), SCM (Supply Chain Management), CIM (Computer Integrated Manufacturing), TQM (Total Quality Management), CONWIP (Constant Work in Process). Devido aos propósitos deste trabalho, foi explicitada aqui principalmente a comparação entre o JIT e a TOC.

\section{Classificação da literatura a respeito da comparação entre a Teoria das Restrições e a Manufatura Enxuta}

Nesta seção, é apresentado o sistema de classificação aqui proposto, bem como a classificação dos trabalhos revisados.

\subsection{O sistema de classificação proposto}

O sistema de classificação proposto baseia-se em quatro categorias principais, indicadas por letras maiúsculas:

- A. Fonte do trabalho;

- B. Método de pesquisa utilizado;

- C. Abrangência da comparação;

- D. Resultados da comparação.

A categoria A foi dividida em duas subcategorias, buscando diferenciar os artigos provenientes de periódicos (P) e de anais de congresso (C).

A categoria B foi organizada de acordo com os métodos de pesquisa presentes nos trabalhos analisados. Foram observados três tipos de métodos de pesquisa, a saber: modelagem e simulação (MS), teórico conceitual (TC) e survey (S).

Bertrand e Fransoo (2002) explicam que a modelagem baseia-se na hipótese de que modelos podem explicar o comportamento ou parte do comportamento dos processos reais ou então capturar os problemas de tomada de decisões enfrentados pelos gestores em operações reais. A simulação tem por objetivo construir um modelo de um processo individual ou em grupo e experimentá-lo por meio 


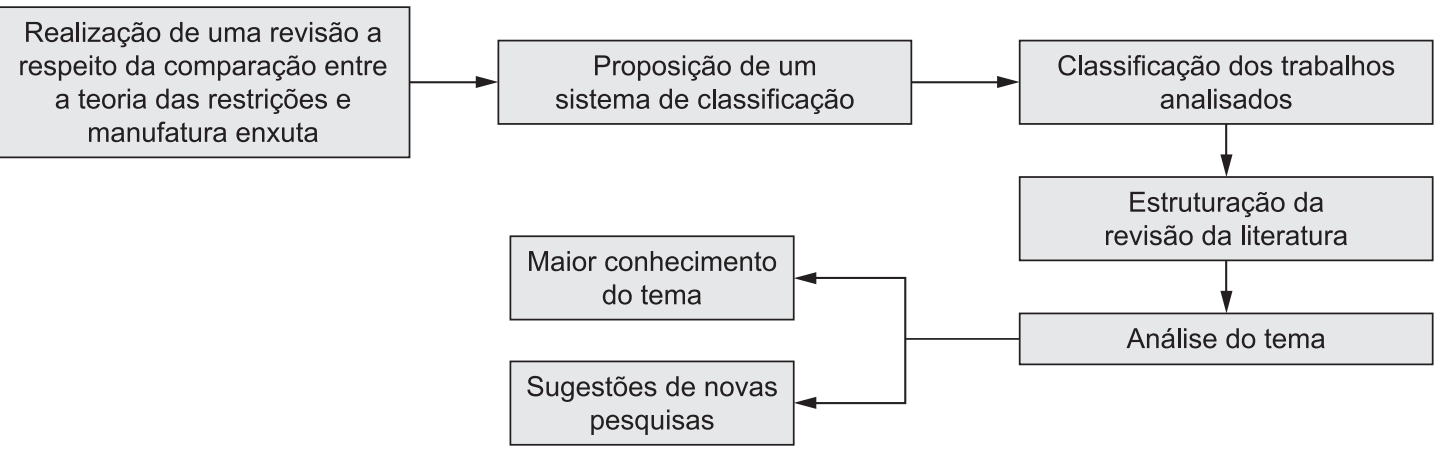

Figura 1. Estrutura metodológica do trabalho. Fonte: Adaptado de Godinho Filho e Fernandes (2003).

da replicação do processo pela manipulação das variáveis e seus inter-relacionamentos dentro do modelo (BERENDS; ROMME, 1999).

A pesquisa do tipo teórico conceitual pode ser definida como sendo um produto de reflexões a partir de um fenômeno observado ou relatado pela literatura (revisão bibliográfica); compilação de ideias e opiniões de diferentes autores ou ainda modelagem teórica (BERTO; NAKANO, 2000).

A pesquisa survey envolve uma coleção de informações sobre indivíduos (por meio de questionários, telefonemas, entrevistas pessoais, etc.) ou sobre a unidade social da qual eles fazem parte (FORZA, 2002). Para Rea e Parker (1992), o processo de amostragem do survey determina informações sobre grandes populações com um nível de precisão conhecido. Segundo Miguel e Lee Ho (2010), neste tipo de pesquisa o pesquisador geralmente avalia uma amostra significativa de um problema a ser investigado a fim de extrair conclusões acerca dessa amostra.

A categoria $\mathrm{C}$ foi dividida em 3 subcategorias. A primeira identifica os artigos que realizam uma comparação geral entre as abordagens TOC e Manufatura Enxuta (C1). Dentro da segunda, se enquadram os trabalhos que realizaram uma comparação entre ferramentas específicas de ambas as abordagens (C2), sendo que nessa classe houve um interesse em apresentar quais as ferramentas comparadas. Já a terceira subcategoria é representada pelos artigos que realizam uma comparação geral tanto entre as abordagens quanto entre as ferramentas específicas (C3).

A categoria $\mathrm{D}$ busca classificar os artigos de acordo com os resultados apresentados, subdividindo-se em 3 subcategorias. A primeira identifica os artigos que apresentam como resultado que uma determinada abordagem/ferramenta se sobressai em alguma situação específica (D1). Nesta subcategoria, houve um interesse em identificar qual foi essa situação específica. Na segunda, se enquadraram os trabalhos que concluem que ambas as abordagens/ ferramentas são complementares (D2). Por fim, a última subcategoria identificou aqueles que não se enquadraram nas categorias anteriores, sendo chamados de outros (D3).

\subsection{Classificação da revisão da literatura a respeito da comparação entre a Teoria das Restrições e a Manufatura Enxuta}

Depois da estrutura do sistema de classificação utilizada ter sido apresentada, foi possível realizar a classificação propriamente dita. Os 33 artigos foram classificados de acordo com o sistema aqui proposto. Essa classificação quanto às quatro categorias é apresentada no Quadro 1. Os artigos foram colocados em ordem cronológica e alfabética dentro do ano de publicação.

\section{A revisão da literatura}

Nesta seção, a revisão da literatura a respeito da comparação entre a Teoria das Restrições e a Manufatura Enxuta é estruturada utilizando-se a classificação proposta na seção 3, mais especificamente as duas últimas categorias: abrangência e resultados da comparação. A revisão foi estruturada dividindo-se primeiramente os artigos de acordo com a abrangência da comparação, ou seja, na seção 4.1, são apresentados os trabalhos que realizaram uma comparação geral entre as abordagens TOC e Manufatura Enxuta. Na seção 4.2, são apresentados os que realizaram uma comparação entre ferramentas específicas de ambas as abordagens. Por fim, a seção 4.3 é representada pelos artigos que realizam uma comparação geral entre as abordagense também entre ferramentas específicas.

Dentro de cada seção, os artigos estão organizados de acordo com os resultados da comparação, ou seja, os trabalhos serão apresentados obedecendo à categoria D do critério do sistema de classificação proposto. Portanto, serão separados os trabalhos que apresentam como resultados que uma determinada abordagem/ferramenta se sobressaiem alguma situação 
Quadro 1. Classificação dos trabalhos da revisão a respeito da comparação entre a Teoria das Restrições e a Manufatura Enxuta.

\begin{tabular}{|c|c|c|c|c|}
\hline Artigo/ano de publicação & $\begin{array}{l}\text { Fonte do } \\
\text { trabalho }\end{array}$ & $\begin{array}{c}\text { Método de } \\
\text { pesquisa } \\
\text { utilizado } \\
\end{array}$ & $\begin{array}{c}\text { Abrangência } \\
\text { da } \\
\text { comparação }\end{array}$ & $\begin{array}{c}\text { Resultados } \\
\text { da } \\
\text { comparação }\end{array}$ \\
\hline AGGARWAL, C. S.; AGGARWAL, S. (1985) & $\mathrm{P}$ & $\mathrm{TC}$ & $\mathrm{C} 3$ & D2 \\
\hline $\begin{array}{l}\text { GELDERS, L. F; WASSENHOVE, L. N. V. } \\
\text { (1985) }\end{array}$ & $\mathrm{P}$ & TC & $\mathrm{C} 1$ & D2 \\
\hline PLENERT, G., BEST, T. D. (1986) & $\mathrm{P}$ & $\mathrm{TC}$ & $\mathrm{C} 3$ & D1 \\
\hline FRY, T.D., BLACKSTONE, J. H. (1988) & $\mathrm{P}$ & $\mathrm{TC}$ & $\mathrm{C} 1$ & D3 \\
\hline $\begin{array}{l}\text { LAMBRECHT, M. R.; DECALUWE, L. } \\
\text { (1988) }\end{array}$ & $\mathrm{P}$ & MS & $\mathrm{C} 1$ & D2 \\
\hline $\begin{array}{l}\text { GRUNWALD, H.; STRIEKWOLD, P. E. T.; } \\
\text { WEEDA, P. J. (1989) }\end{array}$ & $\mathrm{P}$ & MS & $\mathrm{C} 3$ & D1 \\
\hline LAMBRECHT, M.; SEGAERT, A. (1990) & $\mathrm{P}$ & MS & $\mathrm{C} 2$ & D1 \\
\hline $\begin{array}{l}\text { RAMSAY, S.; BROWN, S.; TABIBZADEH, } \\
\text { K. (1990) }\end{array}$ & $\mathrm{P}$ & MS & $\mathrm{C} 2$ & D1 \\
\hline PTAK, C. (1991) & $\mathrm{P}$ & $\mathrm{TC}$ & $\mathrm{C} 1$ & D2 \\
\hline NEELY, A. D; BYRNE, M. D. (1992) & $\mathrm{P}$ & MS & $\mathrm{C} 1$ & D2 \\
\hline COOK, D.P (1994) & $\mathrm{P}$ & MS & $\mathrm{C} 1$ & D1 \\
\hline $\begin{array}{l}\text { GARDINER, S. C.; BLACKSTONE, J. H.; } \\
\text { GARDINER, L. R. (1994) }\end{array}$ & $\mathrm{P}$ & $\mathrm{TC}$ & $\mathrm{C} 2$ & D1 \\
\hline $\begin{array}{l}\text { CHAKRAVORTY, S. S; ATWATER, J. B } \\
\text { (1996) }\end{array}$ & $\mathrm{P}$ & MS & $\mathrm{C} 1$ & D1 \\
\hline MILTENBURG, J. (1997) & $\mathrm{P}$ & MS & $\mathrm{C} 1$ & D1 \\
\hline HEIN, K. (1999) & $\mathrm{C}$ & $\mathrm{TC}$ & $\mathrm{C} 1$ & $\mathrm{D} 2$ \\
\hline HURLEY, S. F; WHYBARK, D. C. (1999) & $\mathrm{P}$ & MS & $\mathrm{C} 1$ & D1 \\
\hline $\begin{array}{l}\text { MATSUURA, H.; KUROSU, S.; } \\
\text { LEHTIMAKI, A. (1999) }\end{array}$ & $\mathrm{P}$ & $\mathrm{TC}$ & $\mathrm{C} 1$ & D3 \\
\hline BOLANDER, S. F.; TAYLOR, S. G. (2000) & $\mathrm{P}$ & TC & $\mathrm{C} 1$ & D1 \\
\hline DETTMER, H. W. (2001) & $\mathrm{P}$ & $\mathrm{TC}$ & $\mathrm{C} 3$ & D2 \\
\hline FERGUSON, L. (2002) & $\mathrm{C}$ & TC & $\mathrm{C} 1$ & D2 \\
\hline HUANG, H. H. (2002) & $\mathrm{P}$ & MS & $\mathrm{C} 1$ & $\mathrm{D} 2$ \\
\hline NAVE, D. (2002) & $\mathrm{P}$ & $\mathrm{TC}$ & $\mathrm{C} 1$ & D3 \\
\hline LEA, B. R; MIN, H. (2003) & $\mathrm{P}$ & MS & $\mathrm{C} 3$ & D1 \\
\hline SALE, M. L; INMAN, R. A. (2003) & $\mathrm{P}$ & $\mathrm{S}$ & $\mathrm{C} 1$ & D1 \\
\hline $\begin{array}{l}\text { TAKAHASHI, K.; MORIKAWA, K.; CHEN, } \\
\text { Y. C. (2007) }\end{array}$ & $\mathrm{P}$ & MS & $\mathrm{C} 2$ & D1 \\
\hline $\begin{array}{l}\text { VENKATESH. M. A.; WAKCHAURE, V.D.; } \\
\text { KALLURKAR, S. P (2007) }\end{array}$ & $\mathrm{P}$ & S & $\mathrm{C} 1$ & D2 \\
\hline JOLDBAUER, H.; HUBER, A. (2008) & $\mathrm{P}$ & MS & $\mathrm{C} 2$ & D1 \\
\hline $\begin{array}{l}\text { PATTI, A. WATSON, K. J.; BLACKSTONE } \\
\text { JR., J.H. (2008) }\end{array}$ & $\mathrm{P}$ & MS & $\mathrm{C} 2$ & D1 \\
\hline WATSON, K. J.; PATTI, A. (2008) & $\mathrm{P}$ & MS & $\mathrm{C} 2$ & D1 \\
\hline YANYING, C.; BINBIN, J. (2008) & $\mathrm{C}$ & $\mathrm{TC}$ & $\mathrm{C} 1$ & D2 \\
\hline GUPTA, M.; SNYDER, D. (2009) & $\mathrm{P}$ & TC & $\mathrm{C} 3$ & D3 \\
\hline KIM, S.; COX, J. F.; MABIN, V. J. (2009) & $\mathrm{P}$ & $\mathrm{TC}$ & $\mathrm{C} 3$ & D3 \\
\hline WANG, Y.; CAO, J.; KONG, L (2009) & $\mathrm{C}$ & MS & $\mathrm{C} 3$ & D2 \\
\hline
\end{tabular}

Significado das siglas. TC - Teórico-conceitual. MS- Modelagem/Simulação. S - Survey. C1 - Comparação geral entre as abordagens Teoria das Restrições e Manufatura Enxuta. C2 - Comparação entre ferramentas específicas de ambas as abordagens. C3 - Comparação geral tanto entre as abordagens quanto entre as ferramentas específicas. D1 - Artigos que apresentam como resultado que uma determinada abordagem/ferramenta se sobressai em alguma situação específica. D2 - Artigos que concluem que ambas as abordagens/ferramentas são complementares. D3 Artigos que não se enquadraram nas categorias anteriores sendo chamados de outros. 
específica, aqueles que concluem que ambas as abordagens/ferramentas são complementares e, por fim, os que não se enquadraram nas categorias anteriores, sendo chamados de outros.

\subsection{Trabalhos que realizaram uma comparação geral entre asabordagens Teoria das Restrições e Manufatura Enxuta}

De acordo com o sistema de classificação proposto, 18 trabalhos foram incluídos nessa categoria. Desses, 6 mostram que uma determinada abordagem se sobressai em alguma situação específica, 9 mostram que as abordagens são complementares e 3 foram classificados como outros. A seguir, será apresentado, de maneira sucinta, um pouco sobre cada um deles.

\subsubsection{Trabalhos que mostram que uma determinada abordagem se sobressai em alguma situação específica}

Cook (1994) realiza uma modelagem/simulação com o objetivo de comparar as seguintes abordagens: manufatura tradicional (baseada no MRP), JIT e TOC. O ambiente simulado possui padrão de fluxo flow shop, 5 estações de trabalho e um único tipo de produto. Foram utilizadas como medidas de desempenho: throughput (definido como a taxa de saída do sistema produtivo), média do tempo de fluxo, desvio padrão do tempo de fluxo e estoque em processo (WIP-Work in Process) médio. Os resultados mostram que a abordagem tradicional não fornece nenhuma vantagem sobre aTOC ou JIT. Além disso, a TOC obteve maior throughput total e menor desvio padrão do tempo de fluxo. Já com relação à média do tempo de fluxo e ao estoque médio em processo, não houve diferenças significativas entre os três sistemas, e, nesse trabalho, o autor identifica pontos contrastantes e similares entre a TOC e o JIT. Como pontos contrastantes ele afirma que o JIT defende linhas balanceadas e a TOC admite linhas não balanceadas. Outro ponto é que o JIT elimina a dependência entre as estações por meio da eliminação de problemas randômicos e variações no tempo de processamento em cada estação de trabalho. Já a TOC busca reduzir variação apenas no recurso gargalo. Outra diferença é em relação ao lote de transferência e de processamento, pois o JIT pressupõe que os dois sejam iguais e para aTOC eles devem ser diferentes. Como pontos similares, o autor afirma que ambos possuem um interesse comum na melhoria contínua, ênfase na qualidade e na redução do WIP.

Chakravorty e Atwater (1996) também realizam uma modelagem/simulação de forma a comparar linhas de produção controladas por diferentes abordagens, entre elas: manufatura tradicional (linha balanceada),
JIT e TOC. Entretanto os autores utilizam como medida de desempenho apenas o throughput. Desta forma, o autor simula 3 diferentes linhas com padrão de fluxo flow shop, representando cada uma das abordagens. Cada linha foi também simulada utilizando oito níveis de estoque para testar o efeito do estoque sobre o desempenho das três linhas. Como resultados, o artigo identifica que a linha controlada pelo JIT tem o melhor desempenho quando a variabilidade no sistema é baixa. Uma extensão deste fato é que o JIT parece obter maior throughput quando há suficiente estoque. $\mathrm{O}$ artigo também indica que as linhas projetadas de acordo com os princípios da TOC são menos afetadas pela variabilidade dentro do sistema.

Miltenburg (1997) conduz uma modelagem/ simulação de modo a comparar o MRP, JIT e TOC. $\mathrm{O}$ autor efetua a análise de um modelo de produção, que consistiu em um ambiente flow shop com duas estações de trabalho e um único tipo de produto, examinando os tipos de melhorias feitas por cada abordagem e os efeitos delas no desempenho de cada linha. As medidas de desempenho utilizadas por este autor foram: throughput; nível de faltas (shortage); nível de estoques; e tempo de fluxo. Como resultados, o autor afirma que nenhuma das abordagens é melhor em todas as medidas de desempenho. O MRP teve o pior desempenho. O JIT apresentou mínimos níveis de estoques e tempos de fluxo. A TOC alcançou máximo throughput e falta mínima. Baseado na simulação, o autor conclui que a abordagem tradicional (MRP) não deve ser utilizada quando os competidores estão usando o JIT ou a TOC. Ele também afirma que o as melhorias na TOC são focadas nas áreas que mais afetam o nível de throughput, enquanto que no JIT as melhorias não são tão focadas como na TOC.

Hurley e Whybark (1999) realizam uma simulação para investigar diferentes formas de buffering contra incertezas (entre elas, estoque, capacidade excedente e redução da variabilidade) em uma célula de manufatura controlada pelo JIT e outra pela TOC. O modelo de simulação consistiu de 5 estações de trabalho, com padrão de fluxo flow shop, com 3 modelos de um produto, considerando suprimento irrestrito e tempos de setup desprezíveis nas duas primeiras estações. Para o caso da célula controlada pela TOC, a quarta estação foi definida com recurso restritivo. Foram utilizadas como medidas de desempenho: throughput, tempo de fluxo e utilização da capacidade. Os resultados da simulação indicam que, para as duas abordagens, o uso de programas de redução da variabilidade ou de utilização de capacidade excedente deve ser preferível em relação à utilização de estoques, pois implicam em um aumento no throughput da célula. Para ambas asabordagens, há um aumento no throughput quando se utiliza a redução da variabilidade, seguida pelo uso de capacidade excedente e, por último, a utilização de estoques. Outra constatação é que, para os ambientes 
simulados, a TOC apresenta maior throughput, menor tempo de fluxo e maior utilização do que o JIT.

Bolander e Taylor (2000), por meio de uma pesquisa teórica conceitual, explicam a lógica de programação do MRP, JIT e TOC. Ao discutir aspectos como capacidade excedente, WIP e requerimentos de dados, os autores concluem que o JIT tende a funcionar melhor em ambientes de manufatura com fluxo estável, enquanto o MRP tende a funcionar melhor em ambientes com padrão de fluxo job shop. Já a TOC funciona bem em ambos desde que exista um único recurso restritivo no processo. Além disso, os autores concluem que a TOC minimiza os requerimentos de dados e esforços em scheduling, requerendo precisão apenas no recurso restritivo e o JIT requer pouco ou nenhum dado.

Sale e Inman (2003) realizam um survey buscando comparar a evolução no desempenho, em um período de 3 anos, em empresas que adotaram as abordagens TOC, ou JIT, ou ambas em conjunto (JIT/ TOC) ou nenhuma das duas (chamado de manufatura tradicional). Os dados deste survey foram obtidos por meio de questionários enviados às empresas com o intuito de medir o grau que praticam a TOC, JIT ou ambos, e forneceram medidas financeiras e não financeiras a respeito do desempenho da empresa. Foi criado então, um critério único de medição do desempenho baseado em 13 critérios de desempenho financeiros e não financeiros. O peso de cada critério na elaboração deste critério único foi atribuído pelas 180 empresas respondentes. Embasados pela análise dos dados, utilizando análise de variância (ANOVA), os autores concluem que a abordagem TOC apresentou o melhor desempenho e melhoria no desempenho, seguido por JIT/TOC, tradicional e JIT.

\subsubsection{Trabalhos que mostram que ambas as abordagens são complementares}

O artigo de Gelders e Wassenhove (1985) tem como objetivo analisar o quão bem as abordagens de manufatura MRP, JIT e OPT reagem em ambientes em que existem claras restrições de capacidade. Para isso, realizam uma pesquisa do tipo teórico conceitual, e concluem que, ao invés de responder a pergunta qual das três é a melhor, elas deveriam ser integradas formando uma abordagem híbrida. Primeiramente, o OPT planejaria cuidadosamente as restrições no médio prazo, isto é, forneceria um bom programa mestre. O MRP geraria os requerimentos de materiais, funcionando como uma poderosa base de dados para controlar milhares de itens. Finalmente, no curto prazo e para a parte repetitiva da empresa, o JIT seria utilizado para maximizar o throughput, isto é, para obter um alto carregamento de trabalho suavizado, sendo puxado através do sistema com mínimo tempo de fluxo e pequeno WIP.

Lambrecht e Decaluwe (1988) apresentam os diversos problemas relacionados ao MRP e defendem que o JIT e a Teoria das restrições podem lidar com esses problemas. Mais especificamente, o MRP pode ser usado como um sistema de planejamento e a TOC e o JIT em um nível operacional. Os autores, por meio de um modelo de simulação, constatam que o JIT é sensível a mudanças no plano de produção, enquanto a teoria das restrições consegue encontrar o gargalo antecipadamente, tornando possível ao planejador ajustar o plano de produção.

Ptak (1991), por meio de uma pesquisa do tipo teórico conceitual, discute como as abordagens de manufatura MRP/MRP II, JIT, OPT e CIM têm se desenvolvido em resposta às forças de mercado. Depois de analisar em detalhe cada uma das abordagens, o autor conclui que o sucesso futuro da manufatura não pode depender apenas de uma delas, e que a melhor opção é realizar uma combinação entre todas elas.

Neely e Byrne (1992) defendem a ideia de que o JIT, a TOC e o MRP II são na verdade complementares e buscam propor uma estrutura que integre as três abordagens. A estrutura proposta consiste em uma base de dados para promover a integração (MRP II), uma estrutura organizacional que assegure a melhoria contínua (JIT) e um software que gere programações detalhadas para maximizar a lucratividade (OPT). Adicionalmente, os autores examinam alguns aspectos da TOC, por meio de uma modelagem/simulação, com a intenção de examinar o elemento-chave desta abordagem: o gargalo. Mais especificamente, eles investigam como 6 algoritmos de sequenciamento se comportam quando utilizados para programar trabalho em um ambiente com um recurso gargalo. O ambiente simulado foi composto de 9 estações de trabalho, com 20 produtos diferentes e com padrão de fluxo flow shop. Foram utilizadas como medidas de desempenho: throughput, tamanho médio de fila, despesa de operação (medida indiretamente pela média de utilização das máquinas). Como resultados, 5 dos 6 algoritmos testados obtiveram maior desempenho quando levaram em consideração o recurso gargalo, logo, isto sugere que levar em conta o recurso gargalo no scheduling tem efeito positivo no desempenho. Por fim, os autores concluem que a programação do gargalo deve ser um dos primeiros passos no desenvolvimento de uma abordagem integrada de controle de materiais.

Hein (1999), por meio de uma pesquisa teórica, incorpora a análise focada da Teoria das Restrições com as técnicas e disciplinas da Manufatura Enxuta, de modo que a eficácia dos esforços de melhoria contínua aumente. Dessa maneira, o gerenciamento pode focar os esforços de melhoria nas áreas que irão fornecer o maior retorno. O autor propõe também 
utilizar o Gerenciamento Total da Qualidade (TQM) como uma linguagem que facilite a aceitação da Manufatura Enxuta e da TOC como algo maior que uma moda passageira.

Ferguson (2002) utiliza o método de pesquisa teórico conceitual para analisar os principais conceitos do JIT, os links entre seus elementos e discutir os efeitos indesejáveis que podem ocorrer. Em seguida, o autor utiliza a TOC para analisar o JIT e melhorar a sua eficácia, ou seja, o autor busca discutir uma forma de modificar o JIT com o intuito de alcançar o objetivo de fazer mais dinheiro.

Huang (2002) também busca integrar aspectos do MRP, JIT e do OPT em um único modelo. O sistema desenvolvido é chamado de modelo integrado puxado-empurrado sobre o conceito da TOC e visa controlar a manufatura como um todo, por meio da distribuição de peças ou materiais para o sistema produtivo desde o início, de acordo com o programa mestre de produção.Dessa forma, o desempenho do sistema é melhorado, pois envia os materiais exatos para a planta de modo a fazer frente às programações variadas e fornece os materiais que os recursos restrições requerem utilizando a programação puxada. As operações depois do recurso restrição e aqueles recursos não restritivos operam de acordo com a programação empurrada de modo a aumentar a taxa de produção e utilização tanto quanto possível. Para verificar a viabilidade desse sistema, foi realizada uma modelagem/simulação em um ambiente com padrão de fluxo flow shop, com 4 estações de trabalho e com 3 tipos de produtos. Foram utilizadas como medidas de desempenho o throughput, nível de estoque em processo (WIP), taxa de utilização dos recursos e taxa de utilização do recurso gargalo. Os resultados mostram que o modelo integrado obteve maior throughput e utilização nos recursos gargalo e não gargalo do que o JIT e o MRP separadamente, entretanto não consegue alcançar o JIT no que diz respeito a níveis de estoque em processo. $\mathrm{O}$ artigo fornece também um quadro comparativo entre o MRP, JIT e TOC/OPT e, para os propósitos deste trabalho, será apresentada a comparação apenas entre os dois últimos (Quadro 2).

Venkatesh, Wakchaure e Kallurkar (2007) observam que muitos pesquisadores discutem conceitualmente o valor de entender o efeito da implantação conjunta de abordagens de manufatura. Dessa forma, os autores investigam os relacionamentos entre o JIT, TOC, TPM, TQM e o SCMe descrevem os relacionamentos sinérgicos entre eles. Os autores realizaram um survey em 45 empresas da Índia e, como resultado, observam a necessidade de implementação conjunta das abordagens citadas acima de modo a melhorar o desempenho da manufatura.

Os autores Yanying e Binbin (2008) utilizaram o método de pesquisa teórico conceitual para propor um sistema de planejamento e controle da produção, que integra o MRP II, o JIT e a TOC, voltado para a área de serviços. Os autores afirmam que as abordagens acima citadas, de forma isolada, têm alguns defeitos inevitáveis quando usadas por empresas de serviços, poisnão conseguem fornecer os requerimentos necessários de flexibilidade e agilidade impostos pelo ambiente competitivo, mudanças constantes de demanda de mercado e as características dos serviços em si.

\subsubsection{Outros}

Fry e Blackstone (1988) propõem um melhor programa de produção, colocando de maneira otimizada tempos ociosos de modo a minimizar penalidades de atraso e adiantamento da produção. Os autores afirmam que o JIT em sua forma pura é difícil de ser transferido para um ambiente de produção em lote intermitente, mas os princípios básicos podem ser aplicados, isto é, redução dos tempos de setup e utilização de tempos ociosos nas máquinas. Eles assinalam também que a TOC reconhece a necessidade de utilização de ociosidade em algumas estações (não gargalos), e seus procedimentos heurísticos carregam trabalho de modo a utilizar toda a capacidade do gargalo. Por fim,os autores concluem que, à medida que o número de trabalhos na fila aumenta, o tempo computacional para encontrar a solução ótima aumenta, portanto, procedimentos heurísticos mais eficientes precisam ser pesquisados.

Matsuura, Kurosu e Lehtimaki (1999) comparam a forma como as abordagens JIT e OPT são utilizadas na Finlândia e no Japão. Para isso, os autores utilizam o método de pesquisa teórico conceitual de forma a identificar como as abordagens são interpretadas nesses países. Com relação ao JIT, na Finlândia, ele é amplamente visto como uma técnica de produção e controle de estoques. Já no Japão, o JIT é entendido como um conceito maior, um paradigma. Referente ao OPT, no Japão, ele é visto como uma técnica que utiliza o software OPT para a programação em conjunto com uma programação finita, enquanto na Finlândia, é entendido como um conceitoque encontra meios de enfrentar os gargalos. Os autores afirmam que existem diferenças nas práticas de controle e produção utilizadas em ambos os países e concluem que isso se deve às diferentes interpretações dadas a elas em cada país.

Nave (2002) discute teoricamente aspectos básicos do Seis Sigma, Manufatura Enxuta e TOC. $\mathrm{O}$ autor apresenta um modelo que ajuda a entender seus conceitos, efeitos, similaridades diferenças (Quadro 3-neste trabalho foi analisada apenas a comparação entre Manufatura Enxuta e TOC) e auxilia na escolha do mais adequado entre os três. $\mathrm{O}$ modelo consiste em, primeiramente, entender qual a 
ênfase fundamental de cada um dos três. Em seguida, é necessário identificar os relacionamentos entre a teoria primária e o foco primário das ferramentas e do modelo em questão. $\mathrm{O}$ último passo consiste em identificar os efeitos secundários. Como conclusão, o autor afirma que,depois de seguir essa sequência de passos, é possível encontrar a abordagem quese encaixa melhor na cultura da organização.

Quadro 2. Resultados da comparação entre as abordagens JIT e TOC.

\begin{tabular}{|l|l|l|}
\hline \multicolumn{1}{|c|}{ Índice/abordagem } & \multicolumn{1}{|c|}{ JIT } & \multicolumn{1}{c|}{ TOC } \\
\hline Carregamento da produção & $\begin{array}{l}\text { Presume a existência de } \\
\text { recurso finito e controla } \\
\text { a capacidade por meio da } \\
\text { técnica Kanban }\end{array}$ & $\begin{array}{l}\text { Presume a existência de recurso finito. Considera } \\
\text { limitações no gargalo e aquelas do MRP. Ele } \\
\text { combina funções do MRP e do CRP para ser uma } \\
\text { ferramenta de produção e planejamento }\end{array}$ \\
\hline Capacidade balanceada & Necessário & Não necessário \\
\hline Buffer & Nenhum & Posicionado em frente ao gargalo \\
\hline WIP & Nenhum & Baixo \\
\hline Tamanho do lote & $\begin{array}{l}\text { Muito pequeno. O tempo de } \\
\text { setup é reduzido ao mínimo. }\end{array}$ & $\begin{array}{l}\text { Neste modelo o tempo de setup de um gargalo pode } \\
\text { ser reduzido ao mínimo, maximizando o output. }\end{array}$ \\
\hline Production disorder & $\begin{array}{l}\text { Utiliza o Kanban e uma série } \\
\text { de luzes amarelas e vermelhas } \\
\text { para gerenciar a produção. }\end{array}$ & $\begin{array}{l}\text { Utiliza uma programação rígida e buffers para se } \\
\text { prevenir contra flutuações na produção }\end{array}$ \\
\hline Flexibilidade da produção & $\begin{array}{l}\text { Tem a máxima flexibilidade, } \\
\text { devido aos lotes de tamanho } \\
\text { pequeno e ao baixo nível de } \\
\text { estoque. }\end{array}$ & $\begin{array}{l}\text { Pretende programar um baixo nível de estoque e um } \\
\text { tamanho de lote mais flexível. }\end{array}$ \\
\hline Custo & Barato & $\begin{array}{l}\text { Custo situado entre o alto custo do MRP e o baixo } \\
\text { do JIT }\end{array}$ \\
\hline Eliminar desperdício & $\begin{array}{l}\text { Maximizar o throughput efetivo de recursos } \\
\text { gargalos. }\end{array}$ \\
\hline
\end{tabular}

Fonte: Adaptado de Huang (2002).

Quadro 3. Comparações entre ambas as abordagens.

\begin{tabular}{|c|c|c|}
\hline Programa & Manufatura Enxuta & Teoria das restrições \\
\hline Teoria & Remover desperdício & Gerenciar as restrições \\
\hline \multirow{5}{*}{$\begin{array}{l}\text { Linhas gerais de } \\
\text { aplicação }\end{array}$} & 1. Identificar valor & 1. Identificar restrição \\
\hline & 2. Identificar fluxo de valor & 2. Explorar restrição \\
\hline & 3. Fluxo & 3. Subordinar o processo \\
\hline & 4. Puxe & 4. Elevar restrição \\
\hline & 5. Perfeição & 5. Repetir o ciclo \\
\hline Foco & Focada no fluxo & Restrições do sistema \\
\hline \multirow{3}{*}{ Considerações } & $\begin{array}{l}\text { Remoção do desperdício irá melhorar o desempenho } \\
\text { do negócio }\end{array}$ & Ênfase na velocidade e volume \\
\hline & \multirow{2}{*}{ Defende a realização de pequenas melhorias } & Utiliza o sistema existente \\
\hline & & Interdependência entre os processos \\
\hline Efeito primário & Reduz o tempo de fluxo & Acelera o throughput \\
\hline \multirow{6}{*}{$\begin{array}{l}\text { Efeitos } \\
\text { secundários }\end{array}$} & Menor variação & \multirow{2}{*}{ Menos desperdíco/estoque } \\
\hline & Menos estoques & \\
\hline & Throughput uniforme & \\
\hline & Novo sistema contábil & Contabilidade de ganhos \\
\hline & Fluxo - medida de desempenho para os gerentes & $\begin{array}{l}\text { Throughput - medida de desempenho } \\
\text { do sistema }\end{array}$ \\
\hline & Qualidade melhorada & Qualidade melhorada \\
\hline \multirow{2}{*}{ Critícas } & Análise do sistema ou estatística não avaliada & Mínima entrada de trabalhadores \\
\hline & & Análise de dados não avaliada \\
\hline
\end{tabular}

Fonte: Adaptado de Nave (2002). 


\subsection{Trabalhos que realizaram uma comparação entre ferramentas específicas de ambas as abordagens}

Nesta categoria, foram encontrados 7 trabalhos que comparam as ferramentas Kanban e DBR. Todos esses trabalhos mostram que uma determinada ferramenta se sobressai em alguma situação específica. A seguir, serão apresentados os principais resultados/ contribuições de cada um deles.

\subsubsection{Trabalhos que mostram que uma determinada ferramenta se sobressai em alguma situação específica}

Lambrecht e Segaert (1990) realizam uma modelagem/simulação com o objetivo de comparar linhas controladas pelo Kanban e pelo DBR. O ambiente simulado consistiu em 6 estações de trabalho, com padrão de fluxo flow shop, tendo como medida de desempenho somente o throughput das linhas. Como resultado, os autores concluem que o DBR é superior ao Kanban em um ambiente com um nível de estoque de segurança igual em cada estação de trabalho e também em situações em que, além disso, houver pontos de reposição em todas as estações de trabalho.

Ramsay, Brown e Tabibzadeh (1990) realizam uma modelagem/simulação para determinar os benefícios das abordagens empurrada (MRP), puxada (Kanban) e DBR. O ambiente simulado consistiu de quatro estações de trabalho com múltiplos produtos, com variabilidade nos tempos de setup e na capacidade. Como resultados, os autores notaram que a técnica empurrada é suscetível a falhas no reconhecimento de desvios na programação, enquanto o Kanban é sensível à falta de priorização de ordens. Já o DBR é o mais bem sucedido dentre os três.

Gardiner, Blackstonee Gardiner (1994) utilizam o método de pesquisa teórico conceitual para discutir a evolução da TOC e seus componentes DBR e gerenciamento de buffers, comparando-os com o Kanban. Os autores constataram que a programação no DBR permite dois buffers no recurso restrição, sendo o primeiro em frente e o segundo após. O primeiro é uma proteção contra problemas que possam ocorrer no sistema antes do recurso restrição e o segundo evita que o gargalo fique bloqueado. Já o Kanban não autoriza a produção quando o buffer de saída está cheio. Os autores afirmam também que para ambientes com múltiplos produtos o DBR é mais indicado do que o Kanban, pois ele não requer um buffer de material para cada peça em frente a cada recurso.

Takahashi, Morikawa e Chen (2007) realizam uma modelagem/simulação para comparar o desempenho do Kanban com o DBR. O sistema de produção considerado consistiu de 3 estações de trabalho, com padrão de fluxo flow shop, que processa um único tipo de produto. O custo total, composto pelo custo médio da demanda não atendida e pelo número de itens estocados e em processo em cada estágio, foi considerado como medida de desempenho. $\mathrm{O}$ objetivo foi então investigar a influência da taxa de processamento e parâmetros de custo no desempenho da medida utilizada. Os resultados obtidos mostram que o Kanban se torna superior ao DBR quando os itens estocados em buffers que precedem o gargalo são menos importantes. Já o DBR é superior quando os itens estocados no buffer do recurso gargalo são importantes e também em condições em que demandas rejeitadas são um fator importante.

Watson e Patti (2008) investigam se existe diferença no desempenho do JIT e da TOC quando enfrentam paradas não planejadas de máquinas. Com esse objetivo, os autores realizam uma modelagem/ simulação de modo a comparar as ferramentas DBR e Kanban em um ambiente flow shop, com 5 estações de trabalho, que processa um único tipo de produto, com linha não balanceada e supondo paradas de máquina. As medidas de desempenho utilizadas foram: throughput, tempo de fluxo e nível de estoque. As análises dos resultados sugerem que o DBR obtém melhor desempenho do que o Kanban no que diz respeito aos três indicadores. Além disso, o DBR é mais tolerante à variabilidade do sistema e mostrou-se mais robusto do que o Kanban, pois foi capaz de manter os melhores valores relativos aos indicadores para diferentes níveis de estoque estudados.

Patti, Watson e Blackstone Junior (2008) buscam investigar se a forma como é feita a utilização de capacidade excedente, em linhas não balanceadas que enfrentam variabilidade devido a paradas de máquina não planejadas, tem efeito no desempenho do sistema. Para isso, eles desenvolveram uma modelagem/simulação em um ambiente com padrão de fluxo flow shop, com 6 estações de trabalho, um único produto e com lote de transferência e processamento iguais a 1 . A simulação permitiu comparar o desempenho de 3 configurações de capacidade excedente, nas linhas controladas pelas duas abordagens, Kanban e DBR. As 3 configurações de capacidade excedente (mantendo a média da capacidade excedente em todas elas) foram: balanceado, decrescente e crescente. No modelo balanceado, todos os recursos não restritivos possuem a mesma capacidade excedente. No modelo decrescente, o primeiro recurso restritivo possui a maior capacidade excedente, diminuindo de maneira sucessiva até a penúltima estação. No modelo crescente, a primeira estação tem a menor capacidade excedente, aumentando sucessivamente até a penúltima estação. O desempenho foi auferido pelo throughput e tempo de fluxo. Como resultados da simulação, o artigo mostra que o modelo balanceado apresenta melhores resultados que os modelos não balanceados. Outra constatação é que as linhas controladas pelo 
Kanban comportam-se de maneira diferente das controladas pelo DBR quando enfrentam paradas não planejadas de máquina. A explicação para isso seria o fato de o Kanban restringir o fluxo de material entre as máquinas, ou seja, ser suscetível a bloqueio e inábil em suavizar a demanda sobre a capacidade produtiva de uma máquina por meio da produção de WIP temporário entre as máquinas. Adicionalmente, uma vez que os estoques de segurança estejam espalhados pelo sistema ao invés de concentrados apenas no gargalo, o Kanban é mais suscetível a permitir falta de materiais no gargalo. Deste modo, os autores concluem que o DBR é mais robusto que o Kanban, quando o sistema produtivo apresenta paradas de máquina.

Joldbauer e Huber (2008) avaliam o MRP, Kanban, CONWIP (Constant Work in Process) e DBR por meio do nível de serviço e estoque em processo (WIP). Para isso, foi realizada uma modelagem/simulação com o objetivo de investigar questões relativas ao desempenho em nível de serviço, robustez e estabilidade (definida como sendo a sensibilidade da medida de desempenho com relação a mudanças em um único parâmetro do sistema de PCP). $\mathrm{O}$ ambiente simulado consistiu de 6 estações de trabalho, com padrão de fluxo flow shop, com 10 itens diferentes. Referente aos sistemas DBR e Kanban, o artigo constatou que, alterando a variabilidade e os níveis de WIP, o DBR se mostrou mais robusto do que o Kanban. A exceção detectada foi quando a variabilidade aumentou e havia baixos níveis de estoque em processo. Nessa situação, o Kanban superou o DBR. Referente ao nível de serviço, o DBR obteve desempenho superior ao Kanban. Relativo à estabilidade, o Kanban se saiu melhor do que o DBR. Além dessas conclusões, os autores ressaltam que a maior vantagem do DBR sobre o Kanban é que o DBR demanda um número baixo de parâmetros a serem ajustados, o que não acontece com o Kanban.

\subsection{Trabalhos que realizaram uma comparação geral entre as abordagens e também entre ferramentas específicas}

Foram enquadrados 8 trabalhos nessa categoria. Desses, 3 mostram que uma determinada abordagem/ ferramenta se sobressai em alguma situação específica, 3 mostram que as abordagens/ferramentas são complementares e dois foram classificados como outros. Os trabalhos serão brevemente apresentados a seguir.

\subsubsection{Trabalhos que mostram que uma determinadaabordagem/ferramenta se sobressai em alguma situação específica}

Plenert e Best (1986) conduzem uma pesquisa do tipo teórico conceitual a fim de comparar as abordagens MRP, JIT e OPT. Para isso, eles realizam uma comparação relativa a diversos aspectos: carregamento da produção, tamanho dos lotes, gargalos flutuantes, precisão dos dados, programação da produção, flexibilidade e custo. Referente ao carregamento da produção, o JIT e o OPT assumem capacidade finita. Com relação ao tamanho dos lotes, o OPT trabalha com tamanhos de lote variáveis; já o JIT tenta reduzir o tempo de setup de forma a poder trabalhar com lotes menores. Com relação aos gargalos flutuantes, o OPT se previne dessa ocorrência por meio da utilização de uma programação "realística", com estoque de segurança; já no JIT eles não ocorrem, pois a programação da produção é sincronizada pelo Kanban. Sobre a necessidade de precisão dos dados, para o OPT ela é essencial somente nas restrições e no JIT ela é praticamente zero. A programação do OPT é mais completa do que a do JIT, contudo a velocidade de fornecimento de programação no JIT é maior. Com relação à flexibilidade, o JIT é mais flexível que o OPT. Por fim, referente ao custo, o JIT é mais barato que o OPT. Os autores concluem que ambas as abordagens apresentam vantagens em relação ao tradicional sistema MRP.

Grunwald, Striekwold e Weeda (1989) buscam propor uma forma quantitativa de comparar as abordagens MRP, JIT e OPT. A modelagem/simulação realizada teve como medidas de desempenho a eficiência, qualidade e flexibilidade. Os autores concluem que para situações em que a incerteza e complexidade são pequenas, o Kanban é o mais indicado. Já em situações em que a complexidade aumenta, o OPT é o sistema mais indicado.

Lea e Min (2003) analisam o efeito da implementação do JIT e da TOC no desempenho de uma empresa. Para isso, os autores desenvolvem um modelo de simulação composto por 7 estações de trabalho que processa 3 produtos diferentes para estoque (make-to-stock). O desempenho do sistema foi auferido por medidas financeiras (lucratividade de curto e longo prazo) e não financeiras (taxa de atendimento de ordens e WIP). Os autores constatam que o JIT supera a TOC com respeito à lucratividade no longo e curto prazo, nível de serviço e estoque em processo (WIP), devido a diferenças nas políticas de buffer e regras de sequenciamento. Uma contribuição importante do artigo é uma comparação entre as abordagens JIT e TOC, apresentada no Quadro 4.

\subsubsection{Trabalhos que mostram que ambos as abordagens/ferramentas são complementares}

Aggarwal e Aggarwal (1985) utilizam o método de pesquisa teórico conceitual para avaliar as abordagens de manufatura MRP, JIT e TOC. Os 
autores concluem que, apesar dos bilhões de dólares gastos em softwares sofisticados, o real problema na implantação são as pessoas, ou seja, ter de motivá-las a constantemente atualizar o sistema e convencê-las a mudar seus métodos de trabalho. Os autores afirmam que o JIT é bem sucedido porque assume que os empregados estão dispostos a aceitar o desafio e responsabilidade, enquanto o MRP impõe uma disciplina tremenda. Já o OPT tolera distúrbios e requer disciplina moderada. Para os autores, as três abordagens são boas de certa forma e os problemas com as pessoas podem destruir sua eficácia. Eles afirmam ainda que a experiência adquirida ao longo dos anos pode levar os gerentes a utilizarem mais de uma abordagem de gestão da manufatura em conjunto.

Dettmer (2001) tem como premissa básica que uma abordagem híbrida TOC/Manufatura Enxuta é potencialmente mais produtiva e mais fácil de implementar do que uma das duas separadamente. Para desenvolver o trabalho, o autor conduz uma revisão da literatura a respeito dos princípios e ferramentas das duas abordagens, apresentando os pontos similares e contrastantes entre ambas, apresentados no Quadro 5. Como resultados, o artigo propõe um modelo conceitual (Quadro 6) que

Quadro 4. Resumo das similaridades e diferenças entre JIT e TOC.

\begin{tabular}{|c|c|c|c|}
\hline & & JIT & TOC \\
\hline Metas & Aumenta o lucro & $\begin{array}{l}\text { Redução do custo (reduz } \\
\text { desperdício) por meio do } \\
\text { controle da qualidade, garantia da } \\
\text { qualidade e respeito pelas pessoas. }\end{array}$ & $\begin{array}{l}\text { Fazer dinheiro no presente e } \\
\text { também no futuro }\end{array}$ \\
\hline $\begin{array}{l}\text { Requerimento } \\
\text { de dados }\end{array}$ & $\begin{array}{l}\text { Quantidade e acurácia de } \\
\text { dados menor do que as } \\
\text { abordagens tradicionais }\end{array}$ & Requer poucos dados detalhados. & $\begin{array}{l}\text { Dados mais detalhados para o } \\
\text { gargalo e menos detalhados e } \\
\text { precisos para não gargalos }\end{array}$ \\
\hline $\begin{array}{l}\text { Tecnologia para } \\
\text { automação }\end{array}$ & - & $\begin{array}{l}\text { Automação e computação não } \\
\text { necessários }\end{array}$ & $\begin{array}{l}\text { Automação e computação } \\
\text { são requeridos para a } \\
\text { implementação }\end{array}$ \\
\hline $\begin{array}{l}\text { Custo de } \\
\text { implementação }\end{array}$ & - & Baixo & $\begin{array}{l}\text { Alto, devido aos requerimentos } \\
\text { de dados e automação }\end{array}$ \\
\hline $\begin{array}{l}\text { Tamanho do } \\
\text { lote }\end{array}$ & $\begin{array}{l}\text { Tamanho de lote menor, } \\
\text { lote de transferência não } \\
\text { precisa ser igual ao lote de } \\
\text { processamento }\end{array}$ & $\begin{array}{l}\text { Lotes pequenos ao longo de todo } \\
\text { o processo }\end{array}$ & $\begin{array}{l}\text { Lotes grandes para o gargalo e } \\
\text { pequenos para os não gargalos }\end{array}$ \\
\hline $\begin{array}{l}\text { Ferramenta } \\
\text { de controle do } \\
\text { chão de fábrica }\end{array}$ & $\begin{array}{l}\text { Produção é disparada por } \\
\text { dispositivos de controle }\end{array}$ & $\begin{array}{l}\text { Kanbans são utilizados para } \\
\text { autorizar a produção na estação } \\
\text { precedente }\end{array}$ & $\begin{array}{l}\text { Drum- Buffer-Rope (DBR) é } \\
\text { utilizado para liberar a material } \\
\text { para a produção }\end{array}$ \\
\hline $\begin{array}{l}\text { Processo de } \\
\text { scheduling }\end{array}$ & $\begin{array}{l}\text { São necessários poucas } \\
\text { e menos programações } \\
\text { detalhadas comparado com } \\
\text { as abordagens tradicionais }\end{array}$ & $\begin{array}{l}\text { Programação detalhada apenas } \\
\text { para a montagem final, todas as } \\
\text { outras operações são autorizadas } \\
\text { pela montagem final por meio do } \\
\text { uso do Kanban }\end{array}$ & $\begin{array}{l}\text { Programação detalhada para o } \\
\text { gargalo e menos detalhada para } \\
\text { os não gargalos }\end{array}$ \\
\hline $\begin{array}{l}\text { Melhoria } \\
\text { contínua }\end{array}$ & $\begin{array}{l}\text { Treinamento e educação são } \\
\text { importantes }\end{array}$ & $\begin{array}{l}\text { Processo Kaizen, não focado em } \\
\text { uma área específica, mas todas } \\
\text { as pessoas procuram um jeito de } \\
\text { fazer o trabalho melhor. }\end{array}$ & Melhoria focada no gargalo \\
\hline Estoque & $\begin{array}{l}\text { Estoque precisa ser } \\
\text { reduzido, menor que a } \\
\text { abordagem tradicional } \\
(\text { MRP) }\end{array}$ & $\begin{array}{l}\text { Estoque zero é a meta, buffer } \\
\text { depende do número de Kanbans } \\
\text { no sistema }\end{array}$ & $\begin{array}{l}\text { Algum estoque é necessário } \\
\text { para suavizar a produção, a } \\
\text { meta é minimizar o estoque. Os } \\
\text { buffers são colocados em duas } \\
\text { áreas chave: (1) em frente ao } \\
\text { gargalo; (2) na intersecção do } \\
\text { caminho dos não gargalos com } \\
\text { o gargalo. }\end{array}$ \\
\hline $\begin{array}{l}\text { Planejamento } \\
\text { da capacidade }\end{array}$ & $\begin{array}{l}\text { Planejamento finito da } \\
\text { capacidade }\end{array}$ & $\begin{array}{l}\text { Capacidade é planejada por meio } \\
\text { do uso de um Kanban }\end{array}$ & $\begin{array}{l}\text { Capacidade é planejada } \\
\text { por meio de simulacão } \\
\text { computacional }\end{array}$ \\
\hline
\end{tabular}

Fonte: Lea e Min (2003). 
integra ambas as abordagens, de modo a combinar os benefícios e pontos fortes de cada uma, com o intuito de obter melhor desempenho. Para o autor, a TOC oferece uma estrutura para direcionar os esforços do pensamento enxuto aos pontos nos quais ele terá maior efeito.

Wang, Cao e Kong (2009) buscam propor um sistema de controle híbrido Kanban/Conwip baseado na teoria das restrições (TOC), ou seja, tendo em mente que a TOC tem vantagens em lidar com problemas nos recursos restritivos. Ele foi incorporado ao sistema híbrido Kanban/Conwipde forma a obter um melhor desempenho. Para verificar a validade do sistema híbrido proposto, foi feita uma modelagem/ simulação em uma linha de montagem composta por 12 estações de trabalho, com padrão de fluxo flowSshop que processa um único tipo de produto. Foram utilizadas como medidas de desempenho: tempo médio de espera das ordens, WIP e o throughput. Os resultados da simulação mostram que o sistema proposto é capaz de resolver o problema do gargalo, melhorar a produtividade e reduzir o atraso. Além disso, para o ambiente simulado, o sistema híbrido proposto apresenta melhor desempenho (menor WIP e maior taxa de saída) do que o CONWIP e o Kanban/CONWIP.

\subsubsection{Outros}

Gupta e Snyder (2009) apresentam uma revisão da literatura a respeito de trabalhos que comparam de forma integrada as abordagens TOC, MRP e JIT. Em cada seção são apresentados artigos importantes sobre o tema, com suas respectivas metodologias, contribuições e resultados, além de tabelas que mostram o ano de publicação, metodologia utilizada, quais as abordagens analisadas e os principais fatores $\mathrm{e}$ características consideradas nos artigos, conjuntamente com um resumo das principais concordâncias e discordâncias. Os autores afirmam que, apesar da TOC competir efetivamente contra o MRP e JIT, os resultados são ainda inconclusivos devido à maioria dos artigos falharem em um aspecto ou outro, entre eles: exemplos reais modelados, profundidade de características consideradas, rigor da metodologia

Quadro 5. Similaridades e diferenças entre Manufatura Enxuta e TOC.

\begin{tabular}{|c|c|c|}
\hline \multirow{2}{*}{$\begin{array}{c}\text { Similaridades } \\
\text { Manufatura Enxuta e TOC }\end{array}$} & \multicolumn{2}{|c|}{ Diferenças } \\
\hline & Manufatura Enxuta & TOC \\
\hline $\begin{array}{l}\text { Uma metodologia que abrange } \\
\text { todo o sistema }\end{array}$ & $\begin{array}{l}\text { Redução do custo (fixo e variáveis) } \\
\text { é a melhor meio para lucratividade }\end{array}$ & $\begin{array}{l}\text { Custos tem um ponto de diminuição dos } \\
\text { retornos; Throughput (\$) não têm. }\end{array}$ \\
\hline $\begin{array}{l}\text { Melhoria continua e qualidade } \\
\text { são essênciais e a Participação do } \\
\text { trabalhador é chave para o sucesso. }\end{array}$ & $\begin{array}{l}\text { Não há limites para redução do } \\
\text { esforço, espaço, custo e erros } \\
\text { (Perfeição) }\end{array}$ & $\begin{array}{l}\text { Redução do custo é secundário a geração } \\
\text { do throughput. }\end{array}$ \\
\hline Objetivo: aumentar o lucro & $\begin{array}{l}\text { Todas as instâncias para redução } \\
\text { do desperdício são celebradas }\end{array}$ & $\begin{array}{l}\text { Somente redução do desperdício na } \\
\text { restrição tem um efeito imediato }\end{array}$ \\
\hline Valor é definido pelo consumidor & $\begin{array}{l}\text { Recursos são tipicamente } \\
\text { organizado ao redor de produtos } \\
\text { específicos }\end{array}$ & $\begin{array}{l}\text { Recursos são divididos ao longo das } \\
\text { linhas de produtos ou cadeias de valor }\end{array}$ \\
\hline $\begin{array}{l}\text { O fluxo de valor (cadeia de } \\
\text { suprimentos) se extende além da } \\
\text { planta de manufatura }\end{array}$ & $\begin{array}{l}\text { Não diferencia restrições e não } \\
\text { restrições; todas mudanças são } \\
\text { (mais ou menos) igualmente } \\
\text { importantes }\end{array}$ & $\begin{array}{l}\text { Tempo perdido em uma restrição } \\
\text { representa throughput perdido no sistema; } \\
\text { tempo salvo em uma não restrição não } \\
\text { tem valor imediato }\end{array}$ \\
\hline Minimiza o estoque & Buffers são coisas físicas & Buffers de tempo, e não de coisas físicas \\
\hline Pequenos lotes de produção & Enfatiza fluxo unitário & $\begin{array}{l}\text { Reduzir a quantidade de fluxo tanto } \\
\text { quanto possível sem comprometer o fluxo } \\
\text { para a restrição }\end{array}$ \\
\hline Fluxo contínuo (em vez de fila) & $\begin{array}{l}\text { Não diferencia lote de } \\
\text { processamento e transferência }\end{array}$ & $\begin{array}{l}\text { Lote de processamento é diferente do de } \\
\text { transferência }\end{array}$ \\
\hline $\begin{array}{l}\text { Puxado (make-to-order, ao invés } \\
\text { de mate-to-stock) }\end{array}$ & $\begin{array}{l}\text { Procura eliminar toda a } \\
\text { variabilidade; não visa lidar com } \\
\text { incerteza externa (mercado) }\end{array}$ & $\begin{array}{l}\text { Aceita variação ("Murphy") e incerteza } \\
\text { externa (mercado) como um meio de } \\
\text { vida, e se protege contra isso na medida } \\
\text { do possível }\end{array}$ \\
\hline Liberam capacidade oculta & $\begin{array}{l}\text { Sem "rede de segurança"- tudo } \\
\text { funciona ou nada funciona }\end{array}$ & $\begin{array}{l}\text { Nada funciona sempre perfeitamente, } \\
\text { então se planeja para isso }\end{array}$ \\
\hline
\end{tabular}

Fonte: Adaptado de Dettmer (2001). 
Quadro 6. Integrando a Manufatura Enxuta e a Teoria das Restrições.

\begin{tabular}{|c|c|}
\hline 1. Idenfique a restrição do sistema (TOC) & 2. Decida como explorar a restrição do sistema (TOC) \\
\hline Identifique a cadeia de valor (JIT) & Dimensionamento do Kanban (JIT) \\
\hline \multicolumn{2}{|l|}{ Avaliação do produto/quantidade (JIT) } \\
\hline Mapeamento do processo (JIT) & Fluxo unitário (JIT) \\
\hline \multicolumn{2}{|l|}{ Análise de roteiros (JIT) } \\
\hline Determinação da capacidade (TOC) & Planejamento para trás (TOC) \\
\hline Projeto de layout celular (JIT) & "Drum" (TOC) \\
\hline Trabalho padrão (JIT) & * SMED-CCR somente (JIT) \\
\hline \multirow[t]{2}{*}{ Regras e responsabilidades (JIT) } & * Poka- Yoke -CCR somente (JIT) \\
\hline & * Kaizen - CCR somente (JIT) \\
\hline 3. Subordine o restante a decisão no passo 2 (TOC) & Instruções gráficas de trabalho (JIT) \\
\hline \multicolumn{2}{|c|}{\begin{tabular}{|l|l} 
Sinal puxado Kanban (JIT) & s \\
\end{tabular}} \\
\hline "Rope" (TOC) & 4. Eleve a restrição do sistema (TOC) \\
\hline \multicolumn{2}{|l|}{ "Buffer" (TOC) } \\
\hline \multicolumn{2}{|l|}{ ** 5S housekeeping - Não CCR (JIT) } \\
\hline ** SMED - Não CCR (JIT) & 5. Volte ao passo 1, mas tenha cuidado com a inércia (TOC). \\
\hline \multicolumn{2}{|l|}{ ** Manutenção preventiva total - Não CCR (JIT) } \\
\hline \multicolumn{2}{|l|}{ ** Kaizen - Não CCR (JIT) } \\
\hline \multicolumn{2}{|c|}{\begin{tabular}{l|l}
$* *$ Treinamento (JIT, TOC) & \\
\end{tabular}} \\
\hline \multicolumn{2}{|c|}{$\begin{array}{l}\text { Atividades indicadas por um asterisco (*) são um esforço combinado entre engenharia e sistema de operação no } \\
\text { recurso restrição de capacidade (CCR). Essas atividades são desempenhadas fora da programação normal da produção } \\
\text { para minimizar o tempo parado do CCR. Estes são esforços de alta prioridade requeridos para maximizar a capacidade } \\
\text { disponível no CCR. }\end{array}$} \\
\hline \multicolumn{2}{|c|}{$\begin{array}{l}\text { Atividades indicadas por dois asteriscos }(* *) \text { são operações sistêmicas amplas e esforços em recursos que não são } \\
\text { restrições de capacidade (ou seja, todo lugar exceto o CCR). Essas atividades são desempenhadas durantes os turnos } \\
\text { normais, se possível, durante o tempo ocioso entre as produções de trabalho. Estes esforços tem prioridade menor, ao menos } \\
\text { que o não CCR esteja em risco de se tornar um CCR. }\end{array}$} \\
\hline
\end{tabular}

Fonte: Adaptado de Dettmer (2001).

empregada e profundidade da análise estatística realizada.

Kim, Cox e Mabin (2009) relacionam as abordagens JIT e TOC e duas das principais formas pelas quais um sistema de produção tenta atenuar os efeitos negativos da variabilidade: (i) manter estoque de segurança, e/ou, (ii) manter capacidade ociosa nas máquinas. De acordo com os autores, um dos aspectos que diferencia ambas as abordagens é que, enquanto o JIT foca a redução do estoque em processo, tentando atenuar os efeitos da variabilidade por meio da manutenção de uma capacidade balanceada e ociosa (essa capacidade ociosa é conseguida por meio da melhoria contínua), aTOC foca a manutenção de estoque de segurança a fim de maximizar a utilização do gargalo; dessa forma essa abordagem trabalha com linhas não balanceadas. Depois de realizar uma simulação, os autores concluem que a questão importante não é se o melhor é a linha balanceada (JIT) ou a não balanceada (TOC), mas sim aceitar e utilizar níveis apropriados de estoque de segurança e de capacidade ociosa para "proteger" a linha dos efeitos nocivos da variabilidade e também gerenciar continuamente a linha de forma a identificar e melhorar as causas da geração de estoques desnecessários e de problemas com quebras de máquinas.

\section{Análises}

Nesta seção, será apresentada uma análise geral da revisão da literatura realizada, sendo organizada em três subseções: análise geral dos trabalhos; análise dos trabalhos que mostram que uma determinada abordagem/ferramenta se sobressai em alguma situação específica; e análise dos trabalhos que mostram que as abordagens/ferramentas são complementares.

\subsection{Análise geral}

O trabalho foi estruturado de acordo com o sistema de classificação proposto, baseado em quatro categorias, conforme apresentado na seção 3.1. Nas Tabelas 1-4, são mostrados os percentuais e números de trabalhos enquadrados em cada categoria.

Referente à categoria $\mathrm{A}$, nota-se que o número de trabalhos provenientes de periódicos é preponderante e que há poucos trabalhos em congressos abordando o tema. No que diz respeito ao método de pesquisa utilizado, categoria B, vemos que a modelagem/ 
simulação e a pesquisa teórico-conceitual foram mais amplamente empregadas. Ainda sobre o método de pesquisa, foi observada uma relação entre o método e a conclusão do trabalho. Analisando as Tabelas 5, 6, é possível perceber que $75 \%$ dos trabalhos que mostram que uma determinada abordagem/ferramenta se sobressai em alguma situação específica utilizaram o método modelagem e simulação. Já entre aos trabalhos que mostram que as abordagens/ferramentas são complementares, o método mais utilizado foi o teórico conceitual (58,33\%). Essa constatação pode sugerir que, quando o intuito é comparar as abordagens/ ferramentas, os autores buscam se basear em dados quantitativos oriundos da modelagem e simulação e que quando a intenção é mostrar que ambas as abordagens/ ferramentas são complementares, os autores preferem tratar o assunto de maneira conceitual. Dessa forma, parece haver espaço na literatura sobre o tema para simular e/ou estudar quantitativamente a utilização conjunta das duas abordagens, bem como de suas ferramentas para o PCP.

É possível observar também que, referente às categorias $\mathrm{C}, \mathrm{D}$, o número de trabalhos que comparam de maneira geral a TOC e a Manufatura Enxuta é preponderante, assim como os trabalhos que afirmam que uma determinada abordagem se sobressai em alguma situação específica. Vale ressaltar o número alto de trabalhos que buscam integrar as abordagens/ ferramentas. A seguir, discutiremos com mais detalhes os trabalhos, explorando suas conclusões, ou seja, dividiremos a discussão em trabalhos que afirmaram que alguma abordagem e/ou ferramenta se sobressaiu em alguma situação específica e os artigos que defenderam que uma abordagem e/ou ferramenta são complementares.

\subsubsection{Análise dos trabalhos que mostram que uma determinadaabordagem/ ferramentase sobressai em alguma situação específica}

Dos trabalhos analisados, 16 afirmaram que uma abordagem/ferramenta se sobressai em alguma situação específica. Eles são apresentados no Quadro 7 , mostrando o método de pesquisa utilizado, qual abordagem se sobressaiu e em quais variáveis, além

Tabela 1. Número e percentual de trabalhos na categoria A.

\begin{tabular}{lcc}
\hline \multicolumn{1}{c}{ Categoria A - Fonte do trabalho } & Número de artigos & $\begin{array}{c}\text { Porcentagem } \\
(\boldsymbol{\%})\end{array}$ \\
\hline IP - Periódico internacional & 30 & 90,91 \\
IC - Congresso internacional & 3 & 9,09 \\
\hline
\end{tabular}

Tabela 2. Número e percentual de trabalhos na categoria B.

\begin{tabular}{lcc}
\hline \multicolumn{1}{c}{ Categoria B - Método de pesquisa utilizado } & Número de artigos & $\begin{array}{c}\text { Porcentagem } \\
(\boldsymbol{\%})\end{array}$ \\
\hline MS - Modelagem/Simulação & 16 & 48,48 \\
T - Teórico-conceitual & 15 & 45,45 \\
S - Survey & 2 & 6,06 \\
\hline
\end{tabular}

Tabela 3. Número e percentual de trabalhos na categoria C.

\section{Categoria C - Abrangência da comparação} Número de artigos Porcentagem

\begin{tabular}{lcr}
\hline C1 - Comparação geral entre as abordagens TOC e Manufatura Enxuta. & 18 & 54,55 \\
C2 - Comparação entre ferramentas específicas de ambas as abordagens. & 7 & 21,21 \\
C3 - Comparação tanto entre as abordagens quanto entre suas ferramentas & 8 & 24,24 \\
\hline
\end{tabular}

Tabela 4. Número e percentual de trabalhos na categoria D.

\begin{tabular}{lcc}
\multicolumn{1}{c}{ Categoria D - Resultados da comparação } & Número de artigos & $\begin{array}{c}\text { Porcentagem } \\
(\%)\end{array}$ \\
\hline D1 - Determinado abordagem/ferramenta se sobressai em alguma situação & 16 & 48,48 \\
específica & 12 & 36,36 \\
D2 - Abordagens/ferramentas são complementares & 5 & 15,15 \\
D3 - Outros & 5 \\
\hline
\end{tabular}


Tabela 5. Método de pesquisa utilizado nos trabalhos que mostram que uma determinada abordagem/ferramenta se sobressai em alguma situação específica.

\begin{tabular}{ccc}
\hline $\begin{array}{c}\text { Método de } \\
\text { pesquisa }\end{array}$ & $\begin{array}{c}\text { Número de } \\
\text { trabalhos }\end{array}$ & $\begin{array}{c}\text { Porcentagem } \\
(\boldsymbol{\%})\end{array}$ \\
\hline MS & 12 & 75,00 \\
TC & 3 & 18,75 \\
S & 1 & 6,25 \\
\hline
\end{tabular}

Tabela 6. Método de pesquisa utilizado nos trabalhos que mostram que as abordagens/ferramentas são complementares.

\begin{tabular}{ccc}
\hline $\begin{array}{c}\text { Método de } \\
\text { pesquisa }\end{array}$ & $\begin{array}{c}\text { Número de } \\
\text { trabalhos }\end{array}$ & $\begin{array}{c}\text { Porcentagem } \\
(\boldsymbol{\%})\end{array}$ \\
\hline TC & 7 & 58,33 \\
MS & 4 & 33,33 \\
S & 1 & 8,33 \\
\hline
\end{tabular}

da situação/ambiente em que isso foi observado e a abrangência da comparação.

No Quadro 7 é possível observar que os autores chegaram a resultados similares em alguns trabalhos. Bolander e Taylor (2000) e Chakravorty e Atwater (1996) chegam à mesma conclusão de que o JIT funciona melhor em ambientes com menor variabilidade e complexidade, enquanto que para o oposto a TOC é mais indicada. Isso parece se aplicar às suas respectivas ferramentas, pois, de acordo com Grunwald, Striekwold e Weeda (1989), em situações com baixa incerteza e complexidade do sistema o Kanban é indicado, e à medida que a complexidade aumenta, o OPT/DBR é mais indicado. Watson e Patti (2008) reforçam este ponto ao afirmar que o DBR é mais tolerante à variabilidade no sistema do que o Kanban.

Cook (1994) e Miltenburg (1997) observam também que para um padrão de fluxo flow shop e um único tipo de produto, a TOC alcança maior throughput que o JIT. Entretanto, embasado pelos resultados de sua modelagem/simulação, o segundo afirma que o JIT apresentou mínimos níveis de estoques e tempos de fluxo e a TOC alcançou máximo throughput e falta mínima e, além disso, os esforços da TOC são direcionados para as áreas que mais afetam o throughput, enquanto as melhorias do JIT não são tão focadas. Hurley e Whybark (1999) chegam à conclusão de que aTOC também supera o JIT em relação ao throughput, utilização e tempo de ciclo, para um ambiente composto por 5 estações de trabalho, com 3 modelos de um produto, considerando suprimento perfeito e tempos de setup desprezíveis nas duas primeiras estações.

Diversos autores apontam as vantagens da ferramenta DBR sobre o Kanban. Ramsay, Brown e Tabizadeh (1990) apontam que o DBR possui um melhor scheduling, pois o Kanban é particularmente sensível à falta de priorização. Na simulação realizada por Lambrecht e Segaert (1990), o DBR alcança maior throughput que o Kanban em um ambiente com nível de buffer igual em cada estação de trabalho e, também em situações em que existem pontos de reposição em cada estágio produtivo. Gardiner, Blackstone e Gardiner (1994) observam que o DBR atinge o mesmo throughput que o Kanban em um ambiente com múltiplos produtos, utilizando menos estoque. Na simulação realizada por Watson e Patti (2008), o DBR atingiu maiores níveis de desempenho, medido pelo throughput e tempo de fluxo ao mesmo tempo em que reduziu os requerimentos de estoque relativo ao Kanban. Além disso, eles afirmam que o DBR é mais tolerante à variabilidade do sistema e é mais robusto quando enfrenta paradas não planejadas de máquina. As simulações de Patti, Watson e Blackstone Junior (2008) e Joldbauer e Huber (2008) chegaram ao resultado de que o DBR é mais robusto que o Kanban quando enfrenta parada de máquinas. A exceção para isso é apontada pelo segundo, pois, quando a variabilidade aumenta e o nível de estoque é baixo, o Kanban supera o DBR. Este trabalho ainda aponta que o Kanban apresenta maior estabilidade e o DBR alcança melhor nível de serviço. Takashi, Morikawa e Chen (2007) abordam a questão do custo total e, na simulação por eles realizada, o Kanban obteve menor custo total em situações em que os itens estocados em buffers que precedem o recurso gargalo são menos importantes, padrão de fluxo flow shop, 3 estações de trabalho e um único tipo de produto. Já para todas as outras situações, ou seja, quando os itens estocados no buffer do recurso gargalo são importantes e sob condições em que é importante diminuir o número médio de demandas rejeitadas, o DBR obteve menor custo total.

Na simulação realizada por Lea e Min (2003), o JIT superou a TOC com respeito à lucratividade no longo e curto prazos, nível de serviço e estoque em processo, devido a diferenças em regras e políticas de sequenciamento. Entretanto, para Plenert e Best (1986), o OPT é mais completo que o JIT.

Por fim, analisando os trabalhos que afirmam que uma abordagem/ferramenta se sobressai em alguma situação específica é possível perceber que a maioria dos artigos analisados $(56,25 \%)$ afirma que a TOC/ DBR prevalece. Isso é mostrado na Tabela 7.

Tabela 7. Número e percentual de trabalhos que mostram que alguma abordagem/ferramenta prevaleceu em relação à outra.

\begin{tabular}{lcc}
\hline $\begin{array}{c}\text { Abordagem e/ou } \\
\text { ferramenta prevalece }\end{array}$ & $\begin{array}{c}\text { Número de } \\
\text { trabalhos }\end{array}$ & $\begin{array}{c}\text { Porcentagem } \\
(\boldsymbol{\%})\end{array}$ \\
\hline TOC & 9 & 56,25 \\
JIT & 1 & 6,25 \\
$\begin{array}{l}\text { Cada um se sobressai em } \\
\text { uma situação ou aspecto } \\
\text { específico }\end{array}$ & 6 & 37,50 \\
\hline
\end{tabular}




\begin{tabular}{|c|c|c|c|c|c|c|c|c|c|c|}
\hline 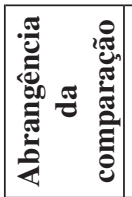 & $\bar{u}$ & $\bar{u}$ & & $\bar{U}$ & & $\bar{u}$ & $\bar{u}$ & & $\bar{u}$ & U \\
\hline 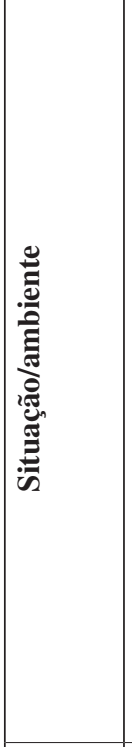 & 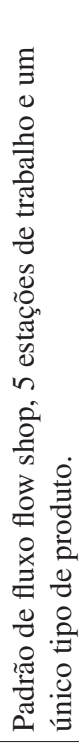 & 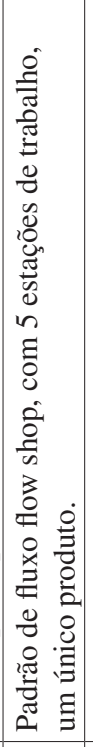 & 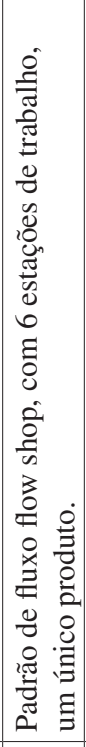 & 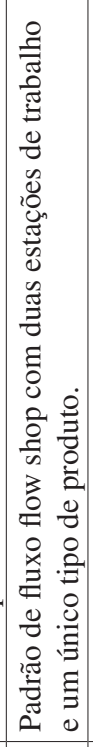 & 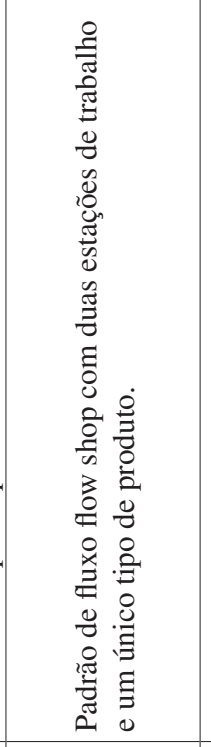 & 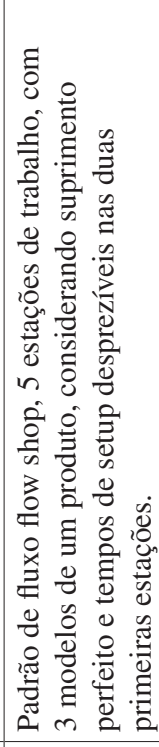 & 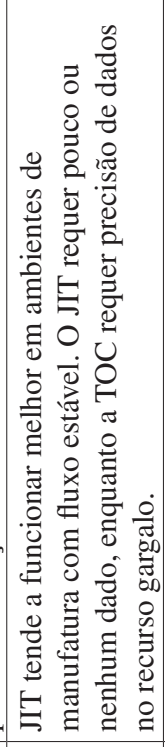 & 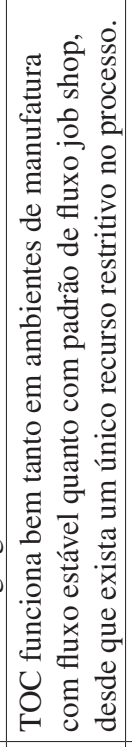 & 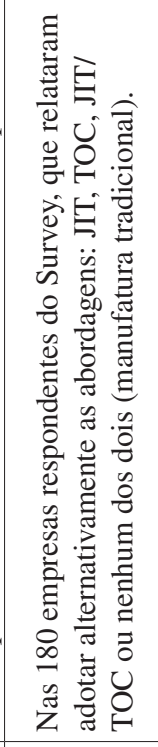 & 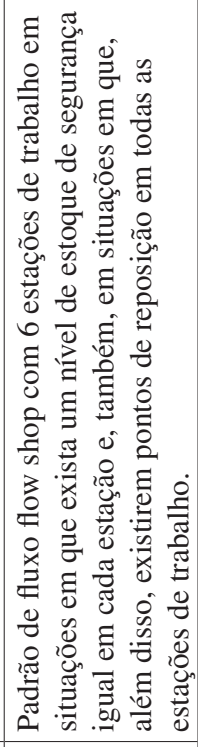 \\
\hline 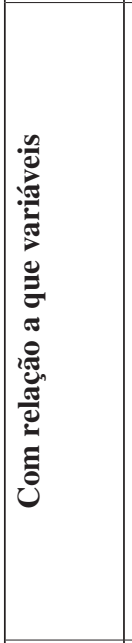 & 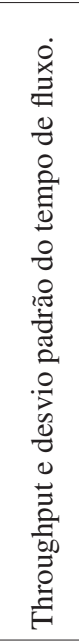 & 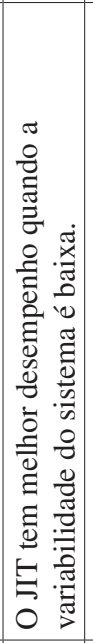 & 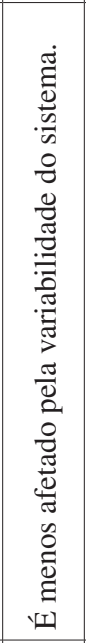 & 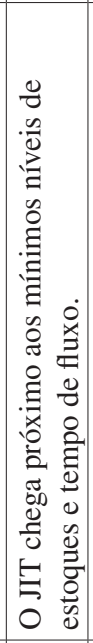 & 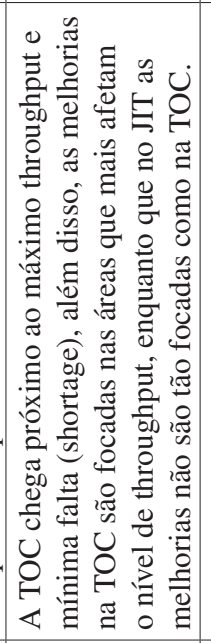 & 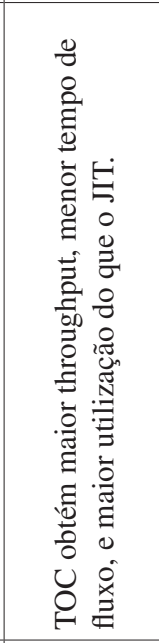 & 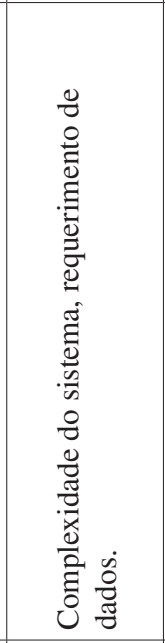 & 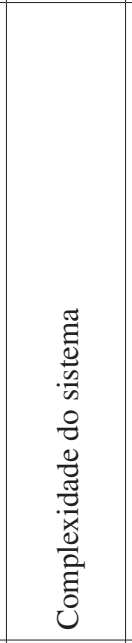 & 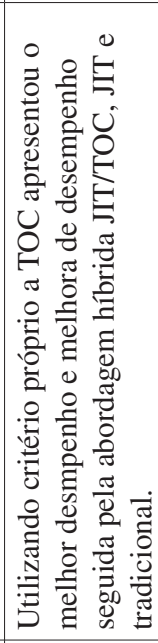 & 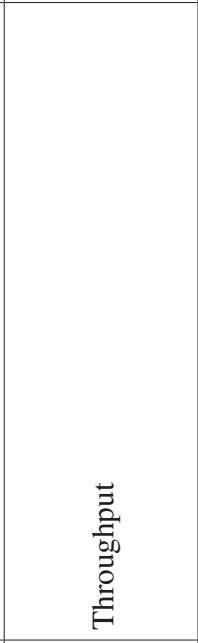 \\
\hline 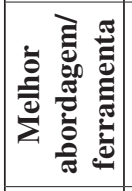 & $\underset{\wp}{\varrho}$ & $\Xi$ & $\underset{\wp}{\circlearrowright}$ & $\Xi$ & $\underset{\wp}{\circlearrowright}$ & $\underset{\wp}{\circlearrowright}$ & $\Xi$ & $\underset{\wp}{\bigcup}$ & $\underset{్}{\circlearrowright}$ & $\frac{q}{\mathscr{0}}$ \\
\hline 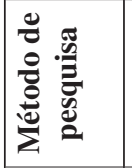 & $\sum_{\Sigma}^{\infty}$ & $\sum_{\Sigma}^{n}$ & & $\Sigma^{n}$ & & $\sum_{\Sigma}^{n}$ & 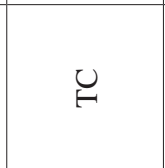 & & $\approx$ & $\sum_{\Sigma}^{n}$ \\
\hline 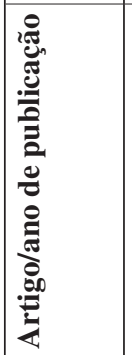 & 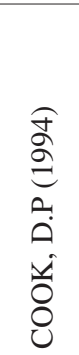 & 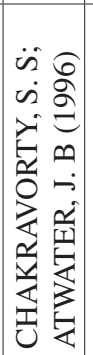 & & 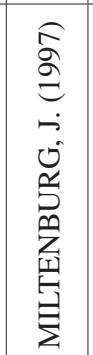 & & 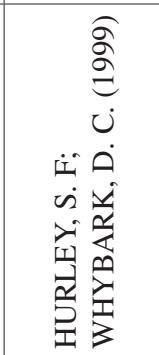 & 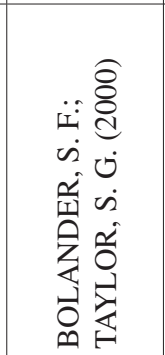 & & 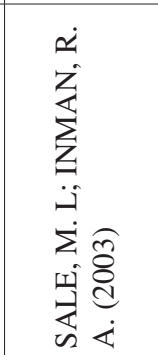 & 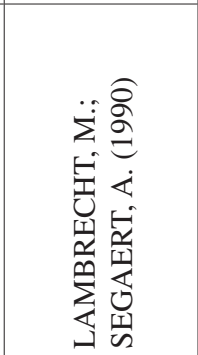 \\
\hline
\end{tabular}




\begin{tabular}{|c|c|c|c|c|c|c|c|}
\hline 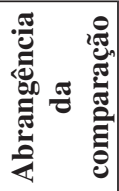 & U & U & U & & U & & \\
\hline 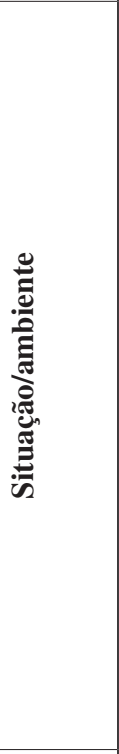 & 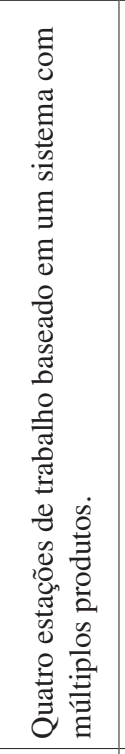 & 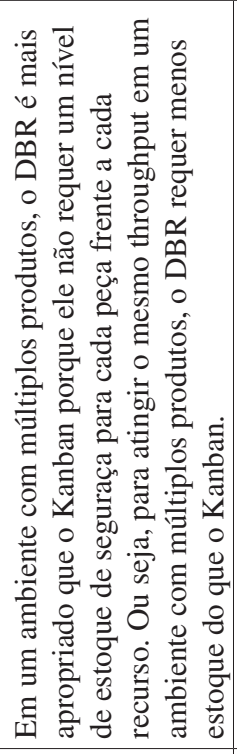 & 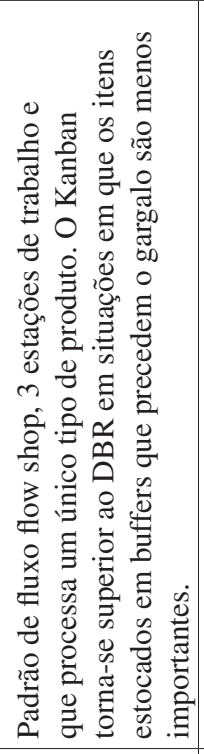 & 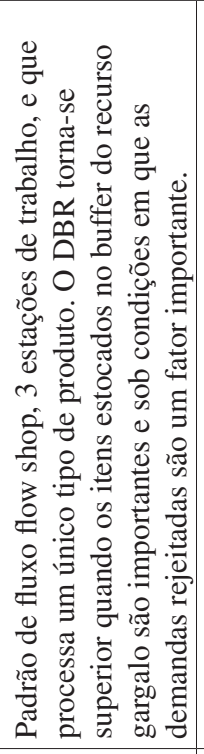 & 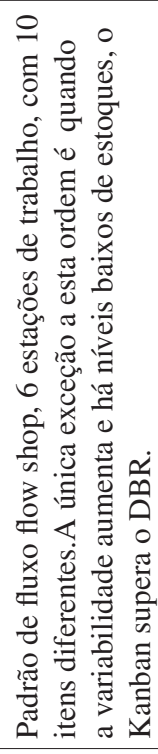 & 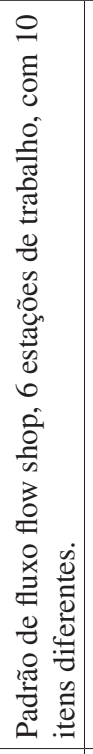 & 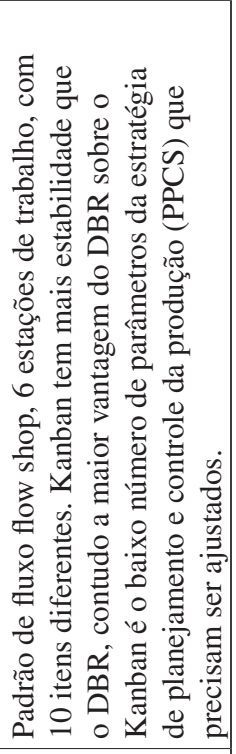 \\
\hline 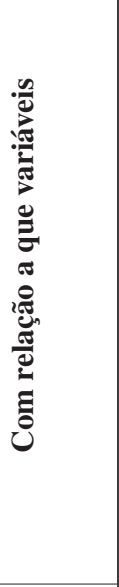 & 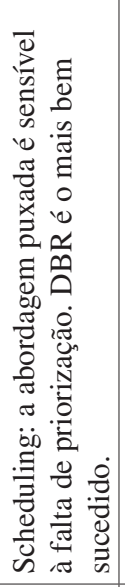 & 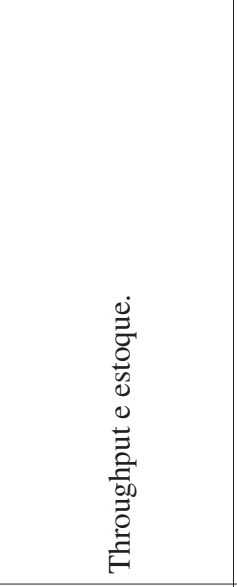 & $\begin{array}{l}\frac{\sigma}{\pi} \\
0 \\
0 \\
0 \\
0 \\
0\end{array}$ & $\begin{array}{l}\frac{\pi}{0} \\
0 \\
0 \\
0 \\
0 \\
0\end{array}$ & $\begin{array}{l}\frac{N}{0} \\
0 \\
\frac{0}{0} \\
\simeq\end{array}$ & 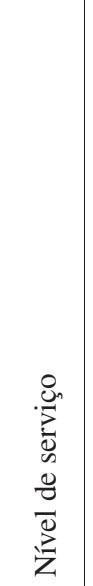 & 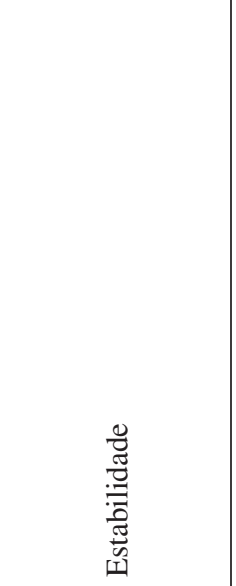 \\
\hline 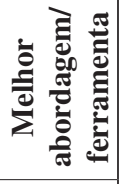 & 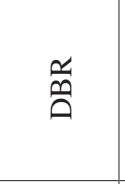 & $\frac{\stackrel{\sim}{m}}{\hat{0}}$ & 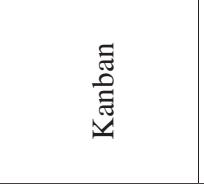 & $\begin{array}{l}\stackrel{\alpha}{0} \\
\stackrel{0}{a}\end{array}$ & 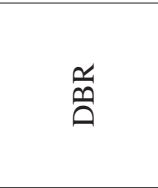 & $\frac{\widetilde{\alpha}}{\stackrel{0}{0}}$ & $\begin{array}{l}\text { I } \\
\text { Е్ } \\
\text { }\end{array}$ \\
\hline 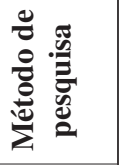 & $\sum^{n}$ & $\underset{H}{U}$ & $\sum^{n}$ & & $\sum^{n}$ & & \\
\hline 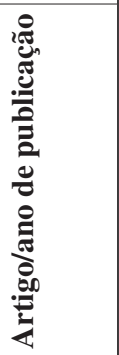 & 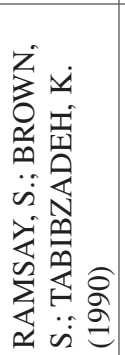 & 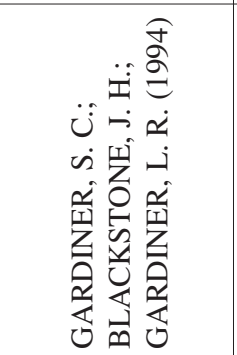 & 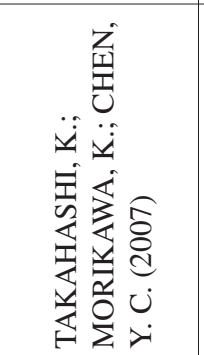 & & 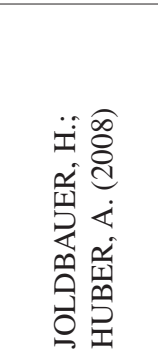 & & \\
\hline
\end{tabular}




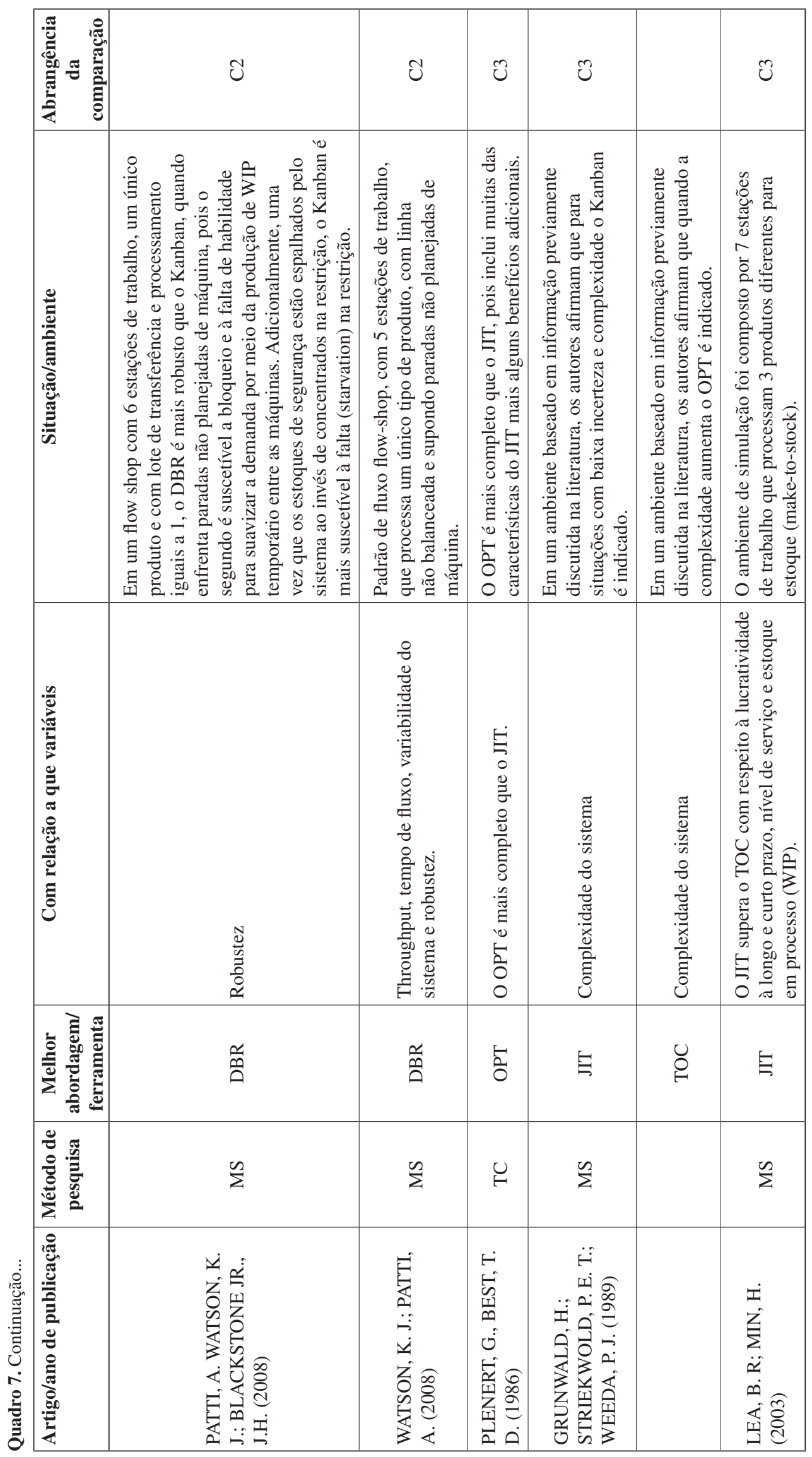




\begin{tabular}{|c|c|c|c|c|c|c|c|}
\hline 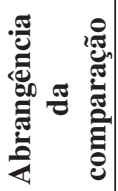 & $\bar{u}$ & $\bar{U}$ & $\bar{u}$ & $\bar{U}$ & $\vec{u}$ & $\bar{U}$ & $\bar{U}$ \\
\hline 苞 & 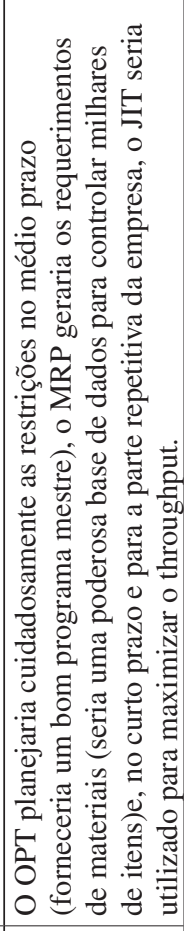 & 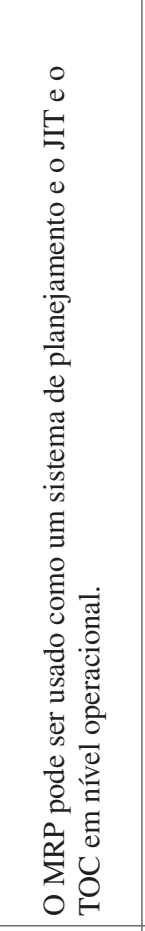 & 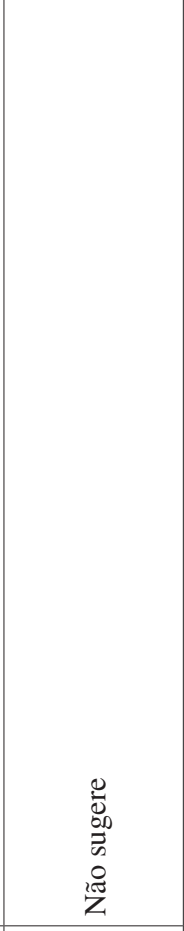 & 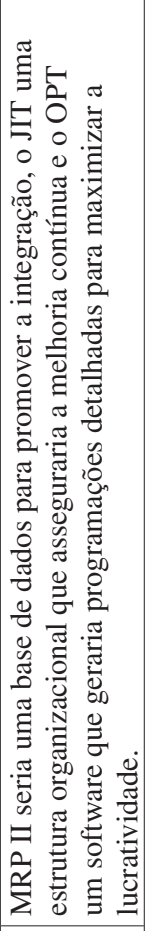 & 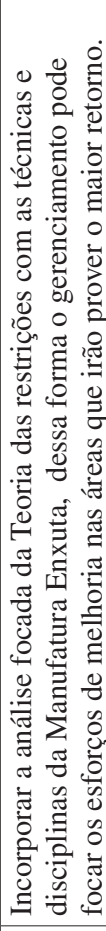 & 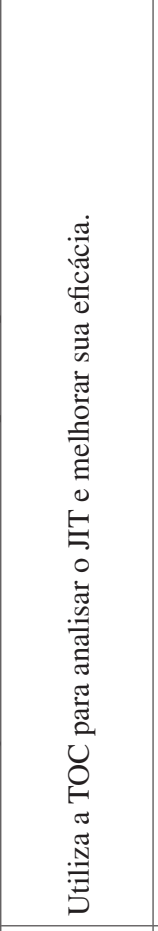 & 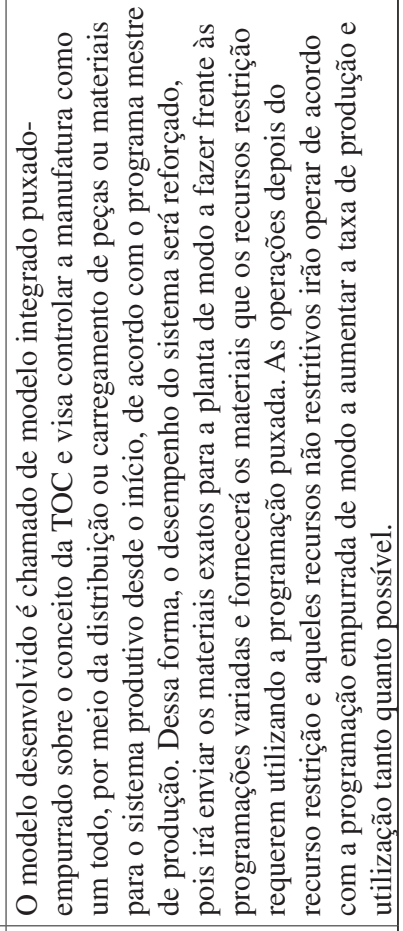 \\
\hline 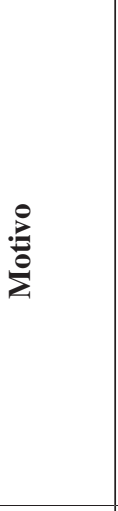 & 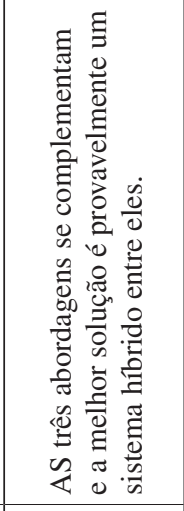 & 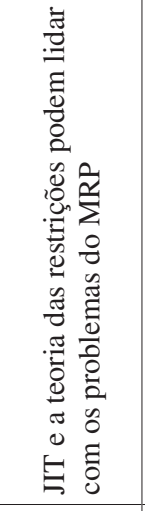 & 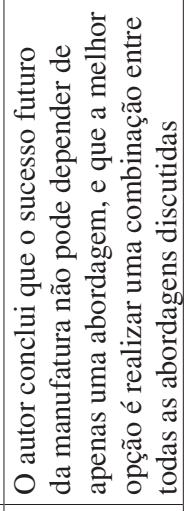 & 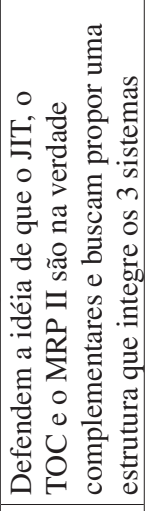 & 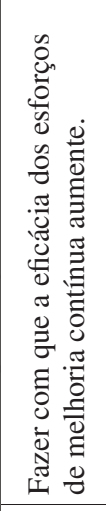 & 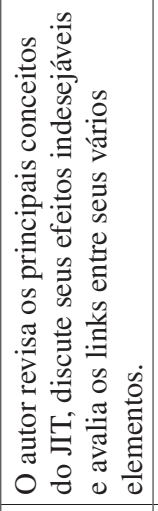 & 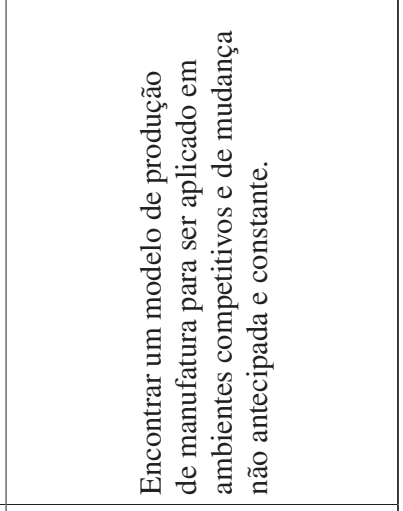 \\
\hline 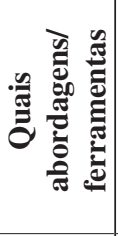 & 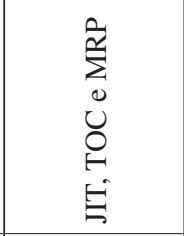 & 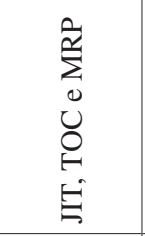 & 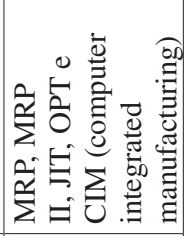 & 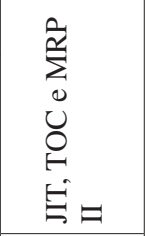 & 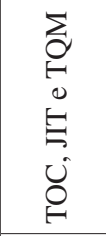 & 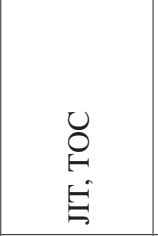 & 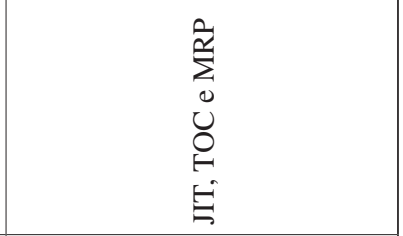 \\
\hline 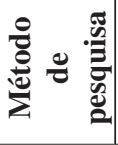 & $\underset{\ominus}{U}$ & $\sum_{\Sigma}^{n}$ & $\underset{\ominus}{U}$ & $\sum_{\Sigma}^{n}$ & $\underset{\varphi}{U}$ & $\underset{\ominus}{U}$ & $\sum^{\infty}$ \\
\hline 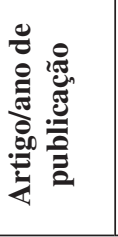 & 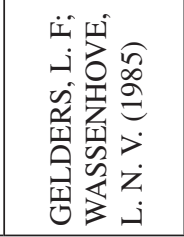 & 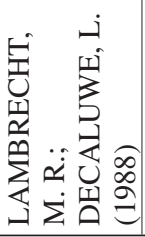 & 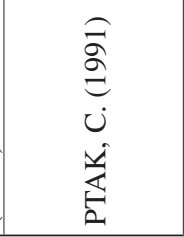 & 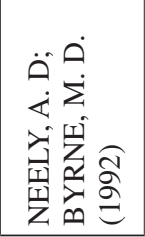 & $\begin{array}{l}\widehat{\sigma} \\
\stackrel{\sigma}{\Xi} \\
\dot{v} \\
z \\
\dot{I}\end{array}$ & 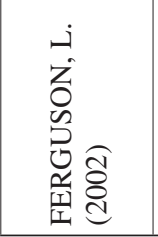 & 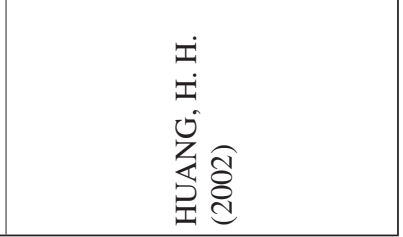 \\
\hline
\end{tabular}




\begin{tabular}{|c|c|c|c|c|c|}
\hline 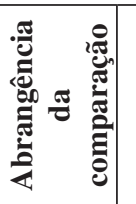 & $\vec{U}$ & U & 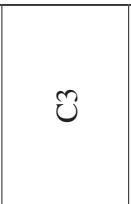 & 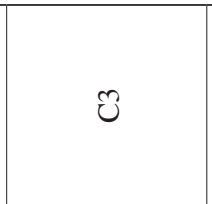 & $\tilde{O}$ \\
\hline : & 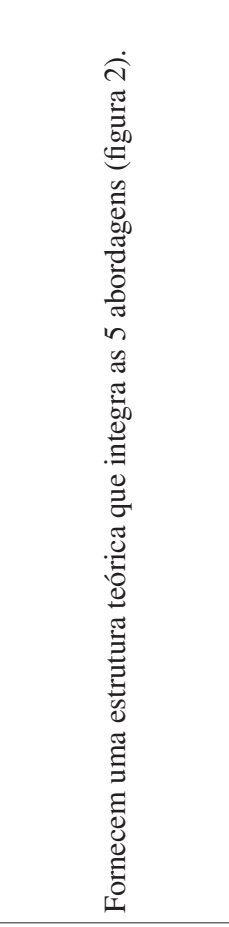 & 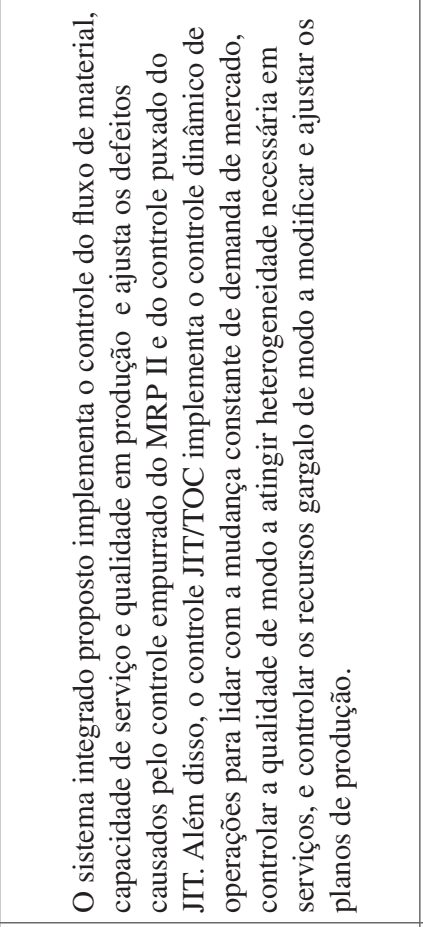 & 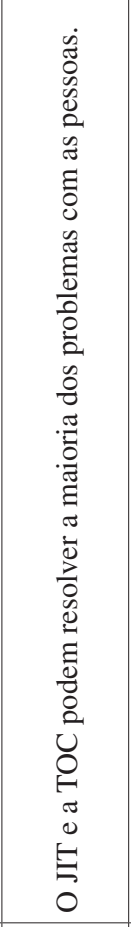 & 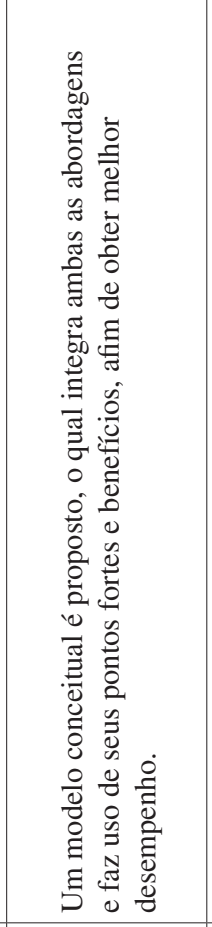 & 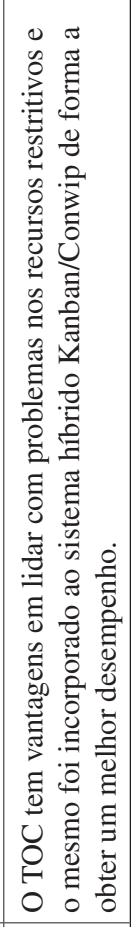 \\
\hline 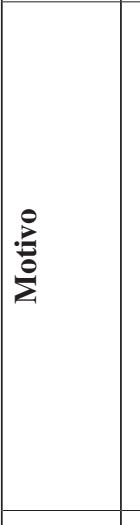 & 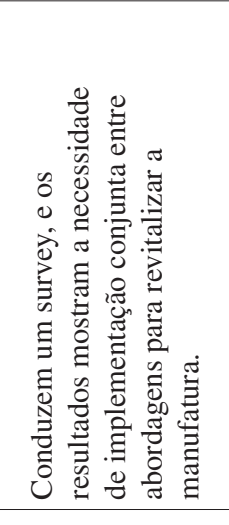 & 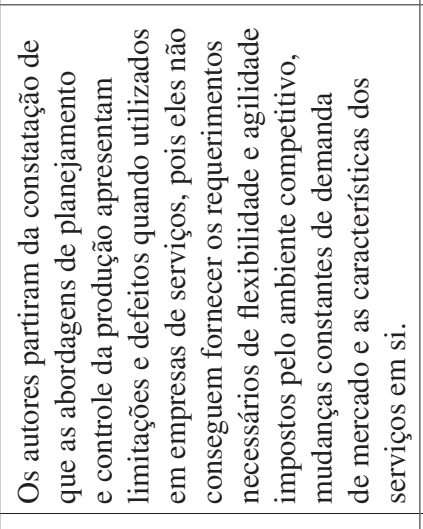 & 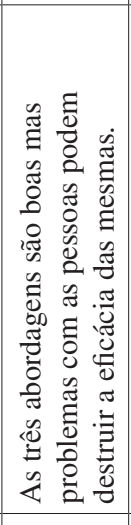 & 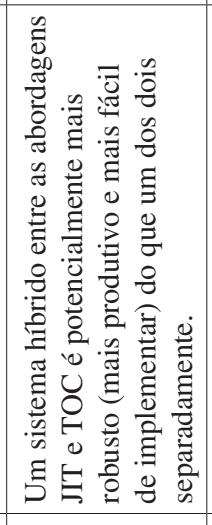 & 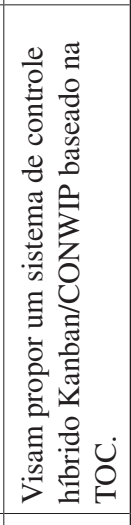 \\
\hline 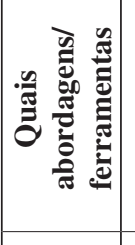 & 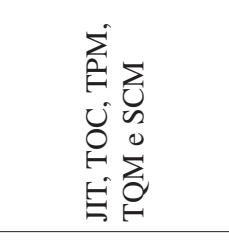 & 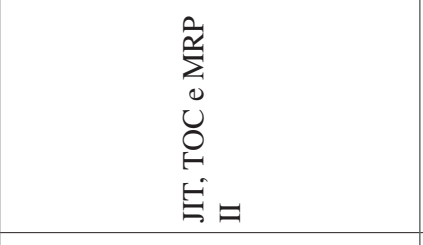 & 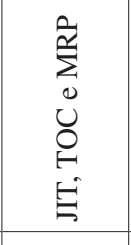 & $\begin{array}{l}\dot{S} \\
\dot{\theta} \\
\dot{0}\end{array}$ & 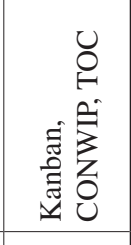 \\
\hline 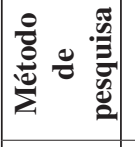 & $n$ & 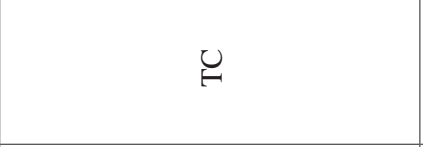 & $\underset{\forall}{U}$ & $\underset{\bullet}{U}$ & $\sum_{\Sigma}^{n}$ \\
\hline 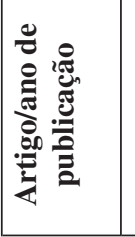 & 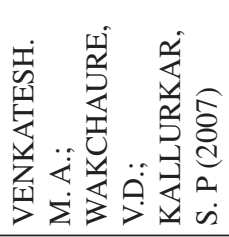 & 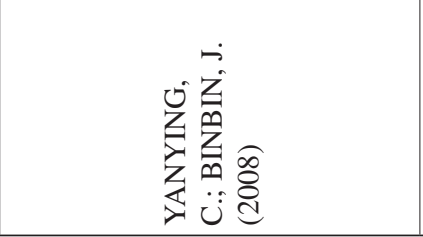 & 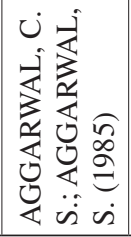 & 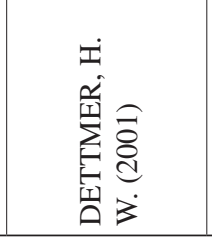 & 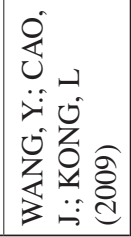 \\
\hline
\end{tabular}




\subsubsection{Análise dos trabalhos que mostram que as abordagens/ferramentas são complementares}

Nesta categoria, foram agrupados todos os trabalhos que consideram as abordagens e/ou ferramentas como sendo complementares, obtendo um total de 12 trabalhos. Os trabalhos desta categoria são apresentados no Quadro 8, mostrando o método de pesquisa utilizado, quais as abordagens/ferramentas foram consideradas complementares, o motivo para isso e a forma de integrá-las. Os trabalhos foram organizados em ordem cronológica e alfabética respeitando primeiramente a abrangência da comparação.

Alguns autores, tais como Hein (1999) e Ferguson (2002) buscam integrar a Manufatura Enxuta e a Teoria das Restrições de modo a melhorar a eficácia dos esforços de melhoria contínua. Dettmer (2001) afirma que a TOC fornece uma boa estrutura em nível de sistemas para direcionar os esforços da Manufatura Enxuta para onde eles terão maior retorno. Ele também propõe a integração das duas abordagens, pois acredita que ela é mais produtiva e fácil de implementardo que uma das duas separadamente.

Gelders e Wassenhove (1985) propõe que o OPT, MRP e o JIT deveriam ser integrados formando um sistema híbrido. O OPT planejaria cuidadosamente as restrições no médio prazo, fornecendo um bom programa mestre, o MRP geraria os requerimentos de materiais, agindo como uma poderosa base de dados para controlar milhares de itens e, no curto prazo e para a parte repetitiva da empresa, o JIT seria utilizado para maximizar o throughput. Neely e Byrne (1992) propõem a integração entre JIT, TOC e MRP II, consistindo de uma base de dados para promover a integração (MRP II), uma estrutura organizacional que asseguraria a melhoria contínua (JIT) e um software que geraria programações detalhadas para maximizar a lucratividade (OPT). Yanying e Binbin (2008) propõem integrar as mesmas abordagens. O sistema integrado proposto implementa um controle de fluxo de materiais, capacidade de serviços e qualidade na produção, e supera os defeitos causados pelo controle empurrado do MRP II e pelo controle puxado do JIT. Além disso, o controle JIT/TOC implementa um controle dinâmico de operações para lidar com a mudança constante de demanda de mercado, controlar a qualidade de modo a atingir heterogeneidade necessária em serviços, e controlar os recursos gargalos de modo a modificar e ajustar os planos de produção. Por fim, Huang (2002) busca integrar o JIT, TOC e MRP de forma a alcançar resposta rápida ao consumidor e aumentar a flexibilidade na produção dos itens.

Já Wang, Cao e Kong (2009) buscam integrar o Kanban, o CONWIP e a TOC, pois acreditam que a TOC tem vantagens em lidar com problemas nos recursos restritivos e foi incorporada ao sistema híbrido Kanban/Conwip de forma a obter um melhor desempenho. Os autores realizam uma simulação e os resultados mostram que o sistema proposto é capaz de resolver o problema do gargalo, melhorar a produtividade e reduzir o atraso. Além disso, para o ambiente simulado, o sistema híbrido proposto apresenta melhor desempenho (menor WIP e a maior taxa de saída) do que o CONWIP e o Kanban/ CONWIP.

Finalmente, podemos ressaltar os autores Ptak (1991) e Venkatesh, Wakchaure e Kallurkar (2007) que propõem a integração de diversas abordagens. Ptak (1991) sugere a integração do MRP, MRP II, JIT, OPT e CIM, porque para ele o sucesso futuro da manufatura não pode depender de apenas um deles, e que a melhor opção é realizar uma combinação entre todas as abordagens discutidas. Já Venkatesh, Wakchaure e Kallurkar (2007) buscam integrar o JIT, TOC, TPM, TQM e SCM, pois acreditam que com sua integração existe potencial para adicionar valor e alcançar uma melhor posição competitiva.

\section{Considerações finais}

O presente estudo teve como objetivo realizar uma revisão da literatura a respeito da comparação entre a Teoria das Restrições e a Manufatura Enxuta, assim como propor um sistema de classificação para os trabalhos, classificando-os de acordo com o sistema proposto e, por fim, efetuando a análise.

O sistema de classificação aqui proposto foi de extrema importância para este trabalho, bem como para a geração de maior conhecimento sobre o tema, pois ele classificou os trabalhos em suas respectivas categorias e estruturou toda a revisão da literatura aqui abordada, tornando o trabalho mais organizado $\mathrm{e}$, consequentemente, facilitando o entendimento.

A análise realizada teve como objetivo aumentar o conhecimento sobre o tema. As principais constatações observadas no decorrer da análise foram:

- De uma forma geral, observou-se a preponderância de trabalhos que buscam comparar as duas abordagens, assim como os que afirmam que uma abordagem/ferramenta se sobressai em alguma situação específica, a qual foi identificada e apresentada no decorrer deste trabalho. Vale ressaltar o grande número de trabalhos que defendem que as abordagens/ ferramentas são na verdade complementares ou que buscam integrá-las.

- Entre os trabalhos que afirmaram que uma determinada abordagem/ferramenta se sobressai em alguma situação específica, $75 \%$ utilizaram o método modelagem/simulação. Já entre os 
trabalhos que mostraram que as abordagens/ ferramentas são complementares, o método mais utilizado foi o teórico conceitual, que ocorreu em 58,33\% dos trabalhos. Essa constatação pode sugerir que, quando o intuito é comparar as abordagens/ferramentas, os autores buscam se basear em dados quantitativos oriundos da modelagem e simulação e que, quando a intenção é mostrar que ambas as abordagens/ferramentas são complementares, os autores preferem tratar o assunto de maneira conceitual. Dessa forma, parece haver espaço na literatura sobre o tema para simular e/ou estudar quantitativamente a utilização conjunta das duas abordagens, bem como de suas ferramentas para o PCP.

- O JIT parece funcionar melhor em ambientes com menor variabilidade e complexidade, enquanto que para o oposto a TOC é mais indicado, de acordo os trabalhos de Bolander e Taylor (2000) e Chakravorty e Atwater (1996).

- A constatação iii parece se aplicar às respectivas ferramentas de cada abordagem, pois, de acordo com Grunwald, Striekwold e Weeda (1989), em situações com baixa incerteza e complexidade do sistema, o Kanban é indicado; e à medida que a complexidade aumenta, o OPT/ DBR é mais indicado. Watson e Patti (2008) reforçam este ponto ao afirmar que o DBR é mais tolerante à variabilidade no sistema do que o Kanban.

- O JIT superaa TOC com respeito à lucratividade no longo e curto prazos, nível de serviço e estoque em processo, em um modelo de simulação composto por 7 estações de trabalho que processa 3 produtos diferentes para estoque, conforme Lea e Min (2003).

- Para Plenert e Best (1986) o OPT é mais completo que o JIT.

- Diversos trabalhos apontam as vantagens de uma ferramenta DBR ou Kanban sobre a outra. As principais constatações a esse respeito foram:

a) O DBR possui um melhor scheduling, conforme Ramsay, Brown e Tabizadeh (1990).

b) O DBR alcança maior throughput que

o Kanban em um ambiente com nível de buffer igual em cada estação de trabalho e, também em situações em que existem pontos de reposição em cada estágio produtivo, de acordo com Lambrecht e Segaert (1990).

c) O DBR atinge o mesmo throughput que o Kanban, em um ambiente com múltiplos produtos, utilizando menos estoque, segundo Gardiner, Blackstone e Gardiner (1994). d) Em um ambiente flow shop, com 5 estações de trabalho, que processa um único tipo de produto, com linha não balanceada e supondo paradas de máquina,Watson e Patti (2008) constataram que o DBR atingiu maiores níveis de desempenho, medido pelo throughput $\mathrm{e}$ tempo de fluxo ao mesmo tempo que reduziu os requerimentos de estoque relativo ao Kanban.

e) Patti, Watson e Blackstone Junior (2008) e Joldbauer e Huber (2008) chegaram ao resultado de que o DBR é mais robusto que o Kanban quando enfrenta parada de máquinas. A exceção para isso é apontada por Joldbauer e Huber (2008), pois quando a variabilidade aumenta e o nível de estoque é baixo, o Kanban supera o DBR. Este trabalho ainda aponta que o Kanban apresenta maior estabilidade e o DBR alcança melhor nível de serviço.

f) De acordo com Takahashi e Morikawa (2007), o Kanban obtém menor custo total em situações em que os itens estocados em buffers que precedem o recurso gargalo são menos importantes, padrão de fluxo flow shop, 3 estações de trabalho e um único tipo de produto. Já para todas as outras situações, ou seja, quando os itens estocados no buffer do recurso gargalo são importantes e sob condiçõesem que é importante diminuir o número médio de demandas rejeitadas, o DBR obtém menor custo total.

- Diversos trabalhos defendem que as abordagens e/ou ferramentas são complementares. As principais constatações observadas foram:

a) Alguns trabalhos, entre eles, os deHein (1999), Ferguson (2002) e Dettmer (2001), buscam integrar a Manufatura Enxuta e a Teoria das Restrições de modo a melhorar a eficácia dos esforços de melhoria contínua. Dettmer (2001) acredita também que a integração das duas abordagens é mais produtiva e fácil de implementar do que uma das duas separadamente.

b) Gelders e Wassenhove (1985) propõe que o OPT, MRP e o JIT deveriam ser integrados formando um sistema híbrido, de forma que o OPT forneceria um bom programa mestre, $\mathrm{o}$ MRP seria uma poderosa base de dados e o JIT seria utilizado para maximizar o throughput.

c) Neely e Byrne (1992) propõem a integração entre JIT, TOC e MRP II, consistindo de uma base de dados para promover a integração (MRP II), uma estrutura organizacional que 
asseguraria a melhoria contínua (JIT) e um software que geraria programações detalhadas para maximizar a lucratividade (OPT).

d) Yanying e Binbin (2008) propõem integrar o JIT, TOC e o MRP II de modo a superar os defeitos causados pelo controle empurrado do MRP II e pelo controle puxado do JIT.

e) Huang (2002) busca integrar o JIT, TOC e MRP de forma a alcançar resposta rápida ao consumidor e aumentar a flexibilidade na produção dos itens.

f) Wang, Cao e Kong (2009) buscam integrar o Kanban, o CONWIP e a TOC, pois acreditam que a TOC tem vantagens em lidar com problemas nos recursos restritivos e foi incorporada ao sistema híbrido Kanban/ CONWIP de forma a obter um melhor desempenho.

g) Ptak (1991) e Venkatesh, Wakchaure e Kallurkar (2007) propõem a integração de diversas abordagens. Ptak (1991) sugere a integração do MRP, MRP II, JIT, OPT e CIM, pois acredita que a melhor opção é realizar uma combinação entre todas essas abordagens. Já Venkatesh, Wakchaure e Kallurkar (2007) buscam integrar o JIT, TOC, TPM, TQM e SCM, pois acreditam que, por meio de sua integração, existe potencial para adicionar valor e alcançar uma melhor posição competitiva.

Por fim, foi observado ao longo dessa revisão que não é possível afirmar que uma das abordagens/ ferramentas seja melhor, pois, mesmo com a predominância de trabalhos afirmando que a TOC/ DBR se sobressai, nota-se que há situações em que o JIT/Kanban também prevalece. Portanto, é necessária uma correta avaliação da empresa e de seu ambiente, que tornará possível escolher adequadamente uma abordagem, ou um híbrido entre elas, de modo a obter os ganhos esperados.

\section{Referências}

AGGARWAL, C. S.; AGGARWAL, S. The management of manufacturing operations: an appraisal of recent developments. International Journal of Production Management, v. 5, n. 3, p. 21-38, 1985. http://dx.doi. org/10.1108/eb054741

BERENDS, P.; ROMME, G. Simulation as a researchtool in management studies. European Management Journal, v. 17, n. 6, p. 576-583, 1999. http://dx.doi.org/10.1016/ S0263-2373(99)00048-1

BERTO, R. M. V. S.; NAKANO, D. N. A produção científica nos anais do Encontro Nacional de Engenharia de Produção: um levantamento de métodos e tipos de pesquisa. Produção, v. 9, n. 2, p. 65-76, 2000. http:// dx.doi.org/10.1590/S0103-65131999000200005

BERTRAND, J. W. M.; FRANSOO, J. C. Operations management research methodologies using quantitative modeling. International Journal of Operations \& Production Management, v. 22, n. 2, p. 241-264, 2002. http://dx.doi.org/10.1108/01443570210414338

BOLANDER, S. F.; TAYLOR, S. G. Scheduling techniques: a comparison of logic. Production and Inventory Management Journal, v.41, n. 1, p. 1-6, 2000.

CHAKRAVORTY, S. S.; ATWATER, J. B. A comparative study of line desing approaches for serial production systems. International Journal of Operations \& Production Management, v.16, n. 6, p. 91-108, 1996. http://dx.doi.org/10.1108/01443579610119117

COOK, D. P. A simulation comparison of traditional, JIT and TOC manufacturing systems in a flow shop with bottlenecks. Production and Inventory Management Journal, 35, p. 73-78, 1994

DETTMER, H. W. Beyond Lean Manufacturing: Combining Lean Manufacturing and the Theory of Constraints for Higher Performance. Port Angeles, 2001. Disponível em: <http:/goalsys.com/books/documents/ TOCandLeanPaper-rev.1.pdf>. Acesso em: 14 ago. 2010.

FERGUSON, L. A. An analysis of JIT using Theory of Constraints (TOC). In: ANNUAL MEETING OF THE DECISION SCIENCES INSTITUTE, 2002, San Diego. Proceedings... Decision Sciences Institute, 2002. p. 1739-1744.

FORZA, C. Survey research in operations management: a processbased perspective. International Journal of Operations \& Production Management, v. 22, n. 2, p. 152-194, 2002. http://dx.doi.org/10.1108/01443570210414310

FRY, T.D.; BLACKSTONE, J. H. Planning for idle time: a rationale for underutilization of capacity. International Journal of Production Research, v. 26 , n. 12 , p. 1853-1859, 1988. http://dx.doi. org/10.1080/00207548808948000

GARDINER, S. C.; BLACKSTONE, J. H.; GARDINER, L. $\mathrm{R}$. The evolution of the theory of constraints. Industrial Management, v. 36, n. 3, p. 13-17, 1994.

GELDERS, L. F.; WASSENHOVE, L. N. V. Capacity planning in MRP, JIT and OPT: a critique. Engineering Costs and Production Economics, n. 9, p. 201-209, 1985. http://dx.doi.org/10.1016/0167-188X(85)90029-1

GODINHO FILHO, M.; FERNANDES, F. C. F. Um sistema para classificar e codificar os trabalhos relacionados com o Controle da Produção e o Controle da Qualidade. Gestão \& Produção, v.10, n.1, 2003.

GOLDRATT, E.; COX, J. The goal: excellence in manufacturing. North River Press, 1984.

GOLDRATT, E. Introduction to TOC - My perspective. In: COX, J. F.; SCHLEIER JUNIOR, J. G. Theory of constraints Handbook. EstadosUnidos da América: Ed. McGraw-Hill, 2010. v. 1, p. 3-9.

GRUNWALD, H.; STRIEKWOLD, P. E. T.; WEEDA, P. J. A framework for quantitative comparison or production control concepts. International Journal of Production Research, v. 27, n. 2, p. 281-292, 1989. http://dx.doi. org/10.1080/00207548908942547 
GUPTA, M.; SNYDER, D. Comparing TOC with MRP and JIT: a literature review. International Journal of Production Research, v. 47, n. 13, p. 3705-3739, 2009. http://dx.doi.org/10.1080/00207540701636322

HEIN, K. Creating continuous improvement synergy with lean and TOC. In: ANNUAL QUALITY CONGRESS TRANSACTIONS, 1999, San Antonio. Proceedings... Annual Quality Congress, 1999. p. 543-549.

HUANG, H. H. Integrated production model in agile manufacturing systems. International Journal of Advanced Manufacturing Technology, v. 20, p. 515-525, 2002. http://dx.doi.org/10.1007/s001700200185

HURLEY, S. F.; WHYBARK, D. C. Inventory and capacity trade-offs in a manufacturing cell. International Journal of Production Economics, v. 59, p. 203-212, 1999. http://dx.doi.org/10.1016/S0925-5273(98)00101-7

JOLDBAUER, H.; HUBER, A. Service-level performance of MRP, Kanban, CONWIP and DBR due to parameter stability and environmental robustness. International Journal of Production Economics, v. 45, n. 8, p. 2179-2195, 2008.

KIM, S.; COX, J. F.; MABIN, V. J.; An exploratory study of protective inventory in a re-entrant line with protective capacity. International Journal of Production Research, v. 48, n. 14, p. 4153-4178, 2009. http://dx.doi. org/10.1080/00207540902991666

LAMBRECHT, M. R.; DECALUWE, L. JIT and constraint theory: The issue of bottleneck management. Production and Inventory Management Journal, 29, p. 61-66, 1988.

LAMBRECHT, M.; SEGAERT, A. Buffer stock allocation in serial and assembly type of production lines. International Journal of Operations and Production Management, v. 10, n. 2, p. 47-61, 1990. http://dx.doi. org/10.1108/01443579010000736

LEA, B. R.; MIN, H. Selection of management accounting systems in Just-In-Time and Theory of Constraints-based manufacturing. International Journal of Production Research, v. 41, n. 13, p. 2879-2910, 2003. http://dx.doi. org/10.1080/0020754031000109134

LIKER, J. K. O modelo Toyota: 14 princípios de gestão da maior fabricante do mundo. Porto Alegre: Bookman, 2005.

MATSUURA, H.; KUROSU, S.; LEHTIMAKI, A. Concepts, practicesandexpectations of MRP, JIT and OPT in Finland and Japan. International Journal of Production Economicas, v. 41, p. 267-272, 1999. http://dx.doi. org/10.1016/0925-5273(95)00067-4

MIGUEL, P. A. C.; LEE HO, L. Levantamento do tipo survey. In: MIGUEL, P. A. C. (Org.). Metodologia de pesquisa em engenharia de produção e gestão de operações. Rio de Janeiro: Elsevier, 2010. p. 73-128.

MILTENBURG, J. Comparing JIT, MRP and TOC, and embedding TOC into MRP. International Journal of Production Research, v. 35, n. 4, p. 1147-1169, 1997. http://dx.doi.org/10.1080/002075497195597

MONDEN, Y. Applying Just in Time: The American/ Japanese experience. Industrial Engineering and Management Press, 1986.
NAVE, D. How to compare Six Sigma, Lean and the Theory of Constraints. Quality Progress, p. 73-78, 2002.

NEELY, A. D.; BYRNE, M. D. A simulation study of bottleneck scheduling. International Journal of Production Economics, v. 26, p. 187-192, 1992. http:// dx.doi.org/10.1016/0925-5273(92)90062-C

OHNO, T. O Sistema Toyota de Produção: além da produção em larga escala. Porto Alegre: Artes Médicas, 1997.

PATTI, A.; WATSON, K. J.; BLACKSTONE JUNIOR, J. H. The shape of protective capacity in unbalanced production systems with unplanned machine downtime. Production and Planning Control, v. 19, n. 5, p. 486-494, 2008. http://dx.doi.org/10.1080/09537280802088733

PLENERT, G.; BEST, T. D. MRP, JIT, and OPT: What's "best"? Production and inventory management, v.27, n. 2, p. 22-28, 1986.

PTAK, C. A. MRP, MRP II, OPT, JIT, - Succession, evolution, or necessary combination. Production and Inventory Management Journal, v. 32, n. 2, p. 7-11, 1991.

RAMSAY, S.; BROWN, S.; TABIBZADEH, K. Push, pulland squeeze shop floor control with computer simulation. Industrial Engineering, v. 22, n. 2, p. 39-45, 1990.

REA, L. M.; PARKER, R. A. Designing and Conducting Survey Research. San Francisco: Jossey-Bass, 1992.

SALE, M. L.; INMAN, R. A. Survey-based comparison of performance and change in performance of firms using traditional manufacturing, JIT and TOC. International Journal of Production Research, v. 41, n. 4, p. 829-844, 2003. http://dx.doi.org/10.1080/0020754031000065520

TAKAHASHI, K.; MORIKAWA, K.; CHEN, Y. C. Comparing Kanban control with the theory of constraints using Markov chains. International Journal of Production Research, v. 45, n. 16, p. 3599-3617, 2007. http://dx.doi.org/10.1080/00207540701228153

VENKATESH, M. A.; WAKCHAURE, V. D.; KALLURKAR, S. P. Synergies of Three Letters Syndrome for Revitalizing Manufacturing. Engineering Letters, v. 14, n. 1, p. 55-60, 2007.

WANG, Y.; CAO, J.; KONG, L. Hybrid Kanban Conwip Control System Simulation. In: IEEE INTERNATIONAL CONFERENCE ON INTELLIGENT COMPUTING AND INTELLIGENT SYSTEMS, 2009, Shanghai. Proceedings... ICIS, 2009.v. 2, p. 666-670.

WATSON, K. J.; PATTI, A. A comparison of JIT and TOC buffering philosophies on system performance with unplanned machine down time. International Journal of Production Research, v. 46, n. 7, p. 1869-1885, 2008. http://dx.doi.org/10.1080/00207540600972943

WOMACK, J. P.; JONES, D. T.; ROOS, D. The machine that changed the world: The story of Lean Production. Nova York: Harper Perennial, 1991.

YANYING, C.; BINBIN, J. Dynamic efficiency and performance improvement to service firms based on integrated MRP II/JIT/TOC system. In: INTERNATIONAL CONFERENCE ON WIRELESS COMMUNICATIONS, NETWORKING AND MOBILE COMPUTINGWICON, 2008, China. Proceedings... China: IEEE, 2008. 